\title{
Snapshot on Negative Electrode Materials for Potassium-Ion Batteries
}

OPEN ACCESS

Edited by:

Renaud Bouchet,

Université Grenoble Alpes, France

Reviewed by:

Manickam Minakshi,

Murdoch University, Australia

Xianwen Wu,

Jishou University, China

*Correspondence:

Romain Berthelot

romain.berthelot@umontpellier.fr

Specialty section:

This article was submitted to Electrochemical Energy Conversion and Storage,

a section of the journal Frontiers in Energy Research

Received: 12 February 2019 Accepted: 26 April 2019

Published: 17 May 2019

Citation:

Gabaudan V, Monconduit L, Stievano $L$ and Berthelot $R$ (2019)

Snapshot on Negative Electrode Materials for Potassium-Ion Batteries.

Front. Energy Res. 7:46.

doi: 10.3389/fenrg.2019.00046

\author{
Vincent Gabaudan ${ }^{1,2}$, Laure Monconduit ${ }^{1,2}$, Lorenzo Stievano ${ }^{1,2}$ and Romain Berthelot ${ }^{1,2 *}$ \\ ${ }^{1}$ ICGM, Université de Montpellier, CNRS, Montpellier, France, ${ }^{2}$ Réseau sur le Stockage Électrochimique de l'Énergie, CNRS, \\ Amiens, France
}

Potassium-based batteries have recently emerged as a promising alternative to lithium-ion batteries. The very low potential of the $\mathrm{K}^{+} / \mathrm{K}$ redox couple together with the high mobility of $\mathrm{K}^{+}$in electrolytes resulting from its weak Lewis acidity should provide high energy density systems operating with fast kinetics. However, potassium metal cannot be implemented in commercial batteries due to its high reactivity. As safety is one of the major concerns when developing new types of batteries, it is therefore crucial to look for materials alternative to potassium metal that electrochemically insert $\mathrm{K}^{+}$at low potential. Here, the different types of negative electrode materials highlighted in many recent reports will be presented in detail. As a cornerstone of viable potassium-ion batteries, the choice of the electrolyte will be addressed as it directly impacts the cycling performance. Lastly, guidelines to a rational design of sustainable and efficient negative electrode materials will be proposed as open perspectives.

Keywords: potassium-ion battery, insertion electrode, alloy electrode, graphite electrode, organic electrodes

\section{INTRODUCTION}

In barely half a century, LIB have evolved from early-stage laboratory discoveries to a massive industrial production. Today, they equip most of our portable electronics and are also considered for powering the next generation electric transportation modes. As our societies are getting everyday more connected and electrified, the production of LIB dramatically continues to increase (Tarascon, 2010). Moreover, the growing part of renewable energy production needs to be supported by an increasing storage capacity, and here again LIB play an important role. However, this impressive success might face practical hurdles in the future. Like other intense human productions, resources shortage or geopolitical tensions may arise. On top of that, after decades of performance improvement, the LIB technology seems to approach its energy density limit (Van Noorden, 2014). For all these reasons, it is important to investigate alternative ways for efficient and sustainable electrochemical energy storage.

Among the possible alternatives to LIB, batteries based on multivalent cations such as $\mathrm{Mg}^{2+}$, $\mathrm{Zn}^{2+}, \mathrm{Ca}^{2+}$, or $\mathrm{Al}^{3+}$ are of interest. Indeed, these elements have a high abundance in Earth's crust suitable to develop "low cost" batteries and the multivalent cations imply the transfer of more than one electron leading to high capacities (Ponrouch et al., 2016; Fang et al., 2018; Ma et al., 2019; Yang $\mathrm{H}$ et al., 2019). However, the design of suitable electrolytes is still a main challenge for all of these systems and significant efforts need to be done in order to reach their promising potential.

Regarding monovalent ions, after decades in the dark, NIB are now focusing the interest of the research community (Chen et al., 2018; Eftekhari and Kim, 2018). Inspired by the wide literature on LIB, NIB have rapidly grew using the similarities in terms of positive/negative electrode material, electrolyte and today the first NIB are commercialized. Going down on the alkali column, KIB come next below and deserve to be highlighted as well. 
For sure, the much bigger size of the $\mathrm{K}^{+}$ions compared to $\mathrm{Li}^{+}$ and $\mathrm{Na}^{+}$will impact directly the materials chemistry inside the battery. Nevertheless, KIB present a number of positive features: (i) the high abundance of potassium on Earth crust compared to lithium, resulting in low cost precursors and salts for battery manufacturing; (ii) Aluminum does not alloy with potassium, allowing cheap $\mathrm{Al}$ current collectors for the negative electrodes; (iii) The low redox potential of the $\mathrm{K}^{+} / \mathrm{K}$ redox couple $(-2.93 \mathrm{~V}$ vs. SHE), very close to the $\mathrm{Li}^{+} / \mathrm{Li}$ one $(-3.04 \mathrm{~V}$ vs. SHE) suitable for developing high energy density batteries; (iv) The weaker Lewis acidity of $\mathrm{K}^{+}$ions compared to $\mathrm{Na}^{+}$and $\mathrm{Li}^{+}$, leading to small Stokes radius in common solvents and therefore providing high ionic diffusion and conductivity. This last point is well described by Kubota et al. who showed that the smaller Stokes radius of $\mathrm{K}^{+}$in $\mathrm{PC}$ compared to those of $\mathrm{Li}^{+}$and $\mathrm{Na}^{+}$results in higher conductivity for the KFSI salt in PC compared to NaFSI and LiFSI whatever the salt concentration (Kubota et al., 2018).

Consequently, an intense research effort has been devoted in the past few years on identifying electrode materials that can electrochemically accommodate potassium ions. Regarding positive electrode materials, layered oxides, polyanionic compounds, and Prussian blue analogs seem to exhibit the most promising behaviors (Zhu et al., 2018; Hosaka et al., 2019). Among them, it is interesting to notice that Mn-based or V-based oxides are also used as cathode materials in $\mathrm{Zn} / \mathrm{MnO}_{2}$ primary cells as well as in rechargeable zinc ion batteries which both are able to work with aqueous based electrolytes (Minakshi et al., 2008; Subbaiah et al., 2015; Zhang N. et al., 2017; Yang S et al., 2019). Prussian blue analogs were also reported as possible cathode material for KIB, using aqueous electrolytes (Wessells et al., 2011; Su et al., 2017). The combination of earth abundant and environmentally benign electrode materials with non-toxic electrolytes is promising for the development of low cost and safety battery systems.

Going back to the KIB, the very high air and moisture sensitivity of potassium precludes its direct use as negative electrode without a reliable chemical or physical surface protection. Luckily, different materials react electrochemically with potassium ions at low potential, and consequently offer promising alternatives to potassium metal negative electrodes. This short review aims at gathering the recent advances in negative electrode materials for $\mathrm{KIB}$, with critical comparison

\footnotetext{
Abbreviations: LIB, Lithium-ion batteries; NIB, Sodium-ion batteries; KIB, Potassium-ion batteries; EC, ethylene carbonate; PC, propylene carbonate; DEC, diethylene carbonate; DMC, dimethylene carbonate; FEC, fluoroethylene carbonate; VC, vinylene carbonate; DME, dimethoxyethane; XRD, X-ray diffraction; XAS, X-ray absorption spectroscopy; PDF, Pair Distribution Function; DFT, density functional theory; SEI, solid electrolyte interphase; LSV, linear sweep voltammetry; PA-Na, sodium polyacrylate; CMC-Na, sodium carboxymethylcellulose; PVdF, polyvinyl difluoride; CVD, chemical vapor deposition; CNT, carbon nanotubes; CNF, carbon nanofibers; HC, hard carbon; SC, soft carbon; TEM, transmission electron microscopy; HRTEM, high resolution transmission electron microscopy; FTIR, Fourier transmission infrared spectroscopy; KFSI, potassium bis(fluorosulfonyl)imide; NaFSI, sodium bis(fluorosulfonyl)imide; LiFSI, lithium bis(fluorosulfonyl)imide; KTFSI, potassium bis(trifluoromethanesulfonyl)imide; $\mathrm{KPF}_{6}$, potassium hexafluorophosphate; rGO, reduced graphene oxide; GIC, graphite intercalation compound; SHE, standard hydrogen electrode.
}

of the cell performance and with a particular attention to the electrolytes and the corresponding electrochemical mechanisms.

\section{GRAPHITE AND CARBON-BASED ELECTRODES}

A wide range of carbon-based materials, such as graphite and derivatives, doped carbons, carbon fibers, carbon nanotubes, mesoporous carbons, and hard carbons have been reported as possible candidates for negative electrode in KIB.

Graphite, the most widespread negative electrode in LIB, is also able to intercalate potassium ions until the formation of $\mathrm{KC}_{8}$, corresponding to a theoretical capacity of $279 \mathrm{mAh} / \mathrm{g}$. This is an important asset compared to the NIB technology, since no insertion of sodium ions in graphite is observed with conventional carbonate electrolytes. This characteristic was confirmed by theoretical calculations of the potential profiles for different GIC and could be explained by the higher redox potential of $\mathrm{Na}^{+} / \mathrm{Na}$ with $-2.71 \mathrm{~V}$ vs. SHE compared to the redox potential of $\mathrm{Li}^{+} / \mathrm{Li}$ and $\mathrm{K}^{+} / \mathrm{K}$ with -3.04 and $-2.93 \mathrm{~V}$, respectively (Okamoto, 2014). The electrochemical intercalation process of potassium ions into graphite was firstly described by Jian et al. (2015), with a staging process and the formation of $\mathrm{KC}_{36}$ and $\mathrm{KC}_{24}$ intermediates revealed by ex situ XRD (Jian et al., 2015) (Figure 1). The moderate cycling performance of graphite electrode especially at high current densities prompted the authors to look at the behavior of softer carbons prepared by pyrolysis of organic aromatic compound. Soft carbons showed higher working potential than graphite with sloping potential profile, less suitable for battery applications, but much better cycling performance and rate capability. At the same time, a slightly different staging process was proposed by Luo et al. based on $a b$ initio calculations with $\mathrm{KC}_{24}, \mathrm{KC}_{16}$, and $\mathrm{KC}_{8}$ respectively formed from stage III to stage I (Luo et al., 2015). The formation of $\mathrm{KC}_{8}$ at the full discharged state characterized by a bronze color was confirmed by ex situ XRD and Raman spectroscopy (Figure 1). Recently, several works centered on XRD experiments rather suggested the formation of $\mathrm{KC}_{36}$ at the stage III and $\mathrm{KC}_{24}$ at the stage II (Beltrop et al., 2017; An et al., 2018; Kubota et al., 2018).

A detailed study about the difference of the potassium ions insertion mechanism in graphite using either carbonate based electrolyte $\left(\mathrm{KPF}_{6}\right.$ in $\left.\mathrm{EC} / \mathrm{DEC}\right)$ or ether based electrolyte $\left(\mathrm{KPF}_{6}\right.$ in monoglyme or diglyme) was carried out by the group of Pint (Cohn et al., 2016; Share et al., 2016a). Operando Raman spectroscopy revealed that free ions are inserted using carbonate solvents, whereas co-intercalation of both ions and solvent occurs with ether-based electrolyte, without however damaging the pristine graphite structure (Figure 2). Thereby, a multi layered graphene electrode exhibited a capacity of $95 \mathrm{mAh} / \mathrm{g}$ at $2 \mathrm{~A} / \mathrm{g}$ after 1,000 cycles with a high coulombic efficiency using $\mathrm{KPF}_{6}$ $(1 \mathrm{M})$ in, diglyme while poor capacity retention was obtained for a few layer graphene electrode at $100 \mathrm{~mA} / \mathrm{g}$ with $\mathrm{KPF}_{6}(0.8 \mathrm{M})$ in $\mathrm{EC} / \mathrm{DEC}$ electrolyte. A similar trend was recently reported by Wang et al. who showed that an electrolyte based on $\mathrm{KPF}_{6}(1 \mathrm{M})$ 

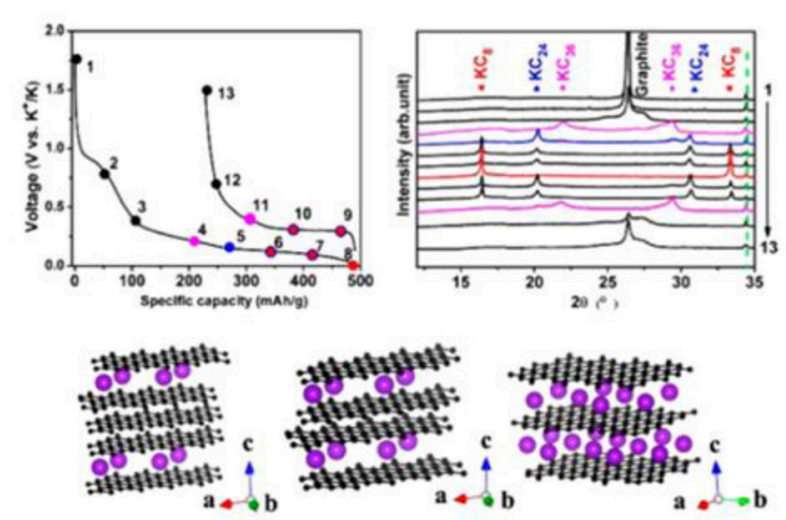

stage 3

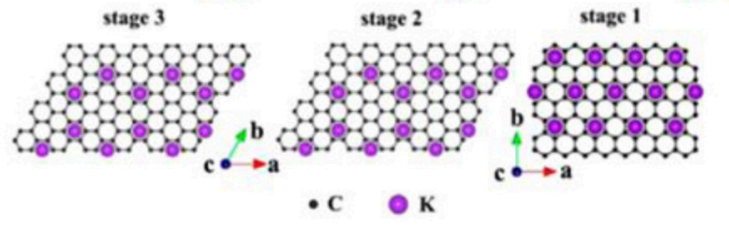

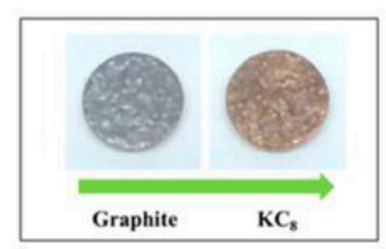
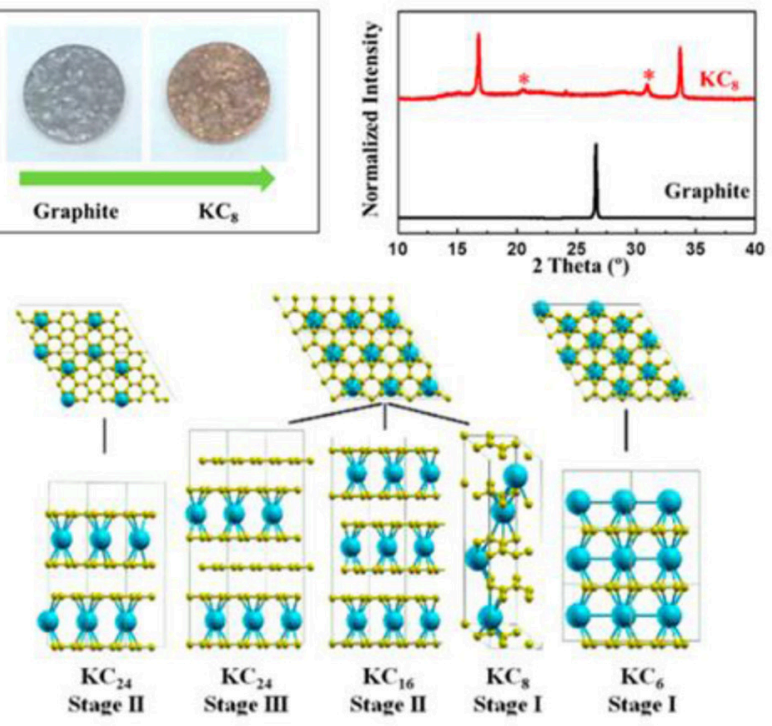

FIGURE 1 | Left, XRD patterns of the electrodes stopped at different point during the first cycle of K/Graphite half cells cycled at C/10 rate, with corresponding structures (Jian et al., 2015). Right, XRD patterns and photo of both pristine and full-discharged graphite electrode *KC24. Right-bottom, structures of the K-GICs proposed by DFT calculations (Luo et al., 2015). Adapted with permission from Jian et al. (2015) and Luo et al. (2015) Copyright (2018) American Chemical Society.

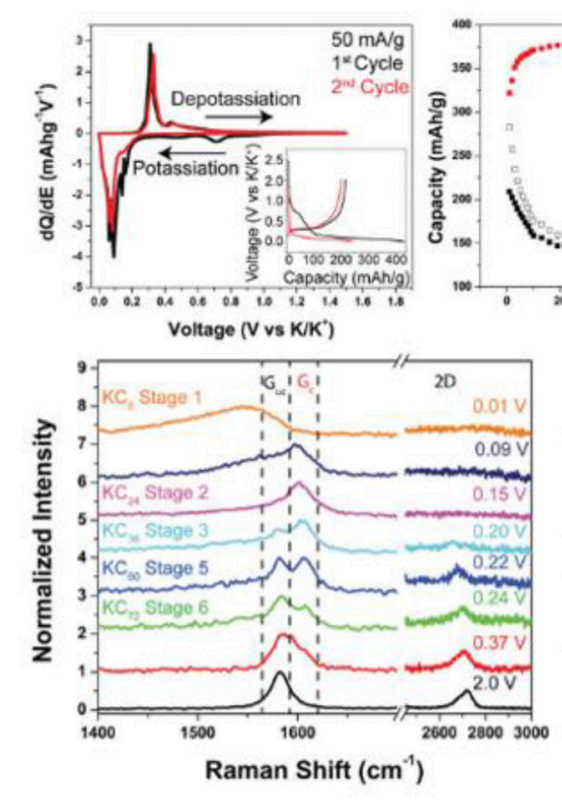

Raman spectra during LSV at $0.5 \mathrm{mV} / \mathrm{s}$. Right-top, electrochemical behavior of natural graphite with ether based electrolyte. Right-bottom, in situ evolution of the

in DME gives rise to a thin SEI and a small expansion of the (002) graphite plane, whereas $\mathrm{KPF}_{6}(1 \mathrm{M})$ in EC/DMC leads to the formation of $\mathrm{KC}_{8}$ with $60 \%$ volume expansion and a thicker SEI (Wang et al., 2019).
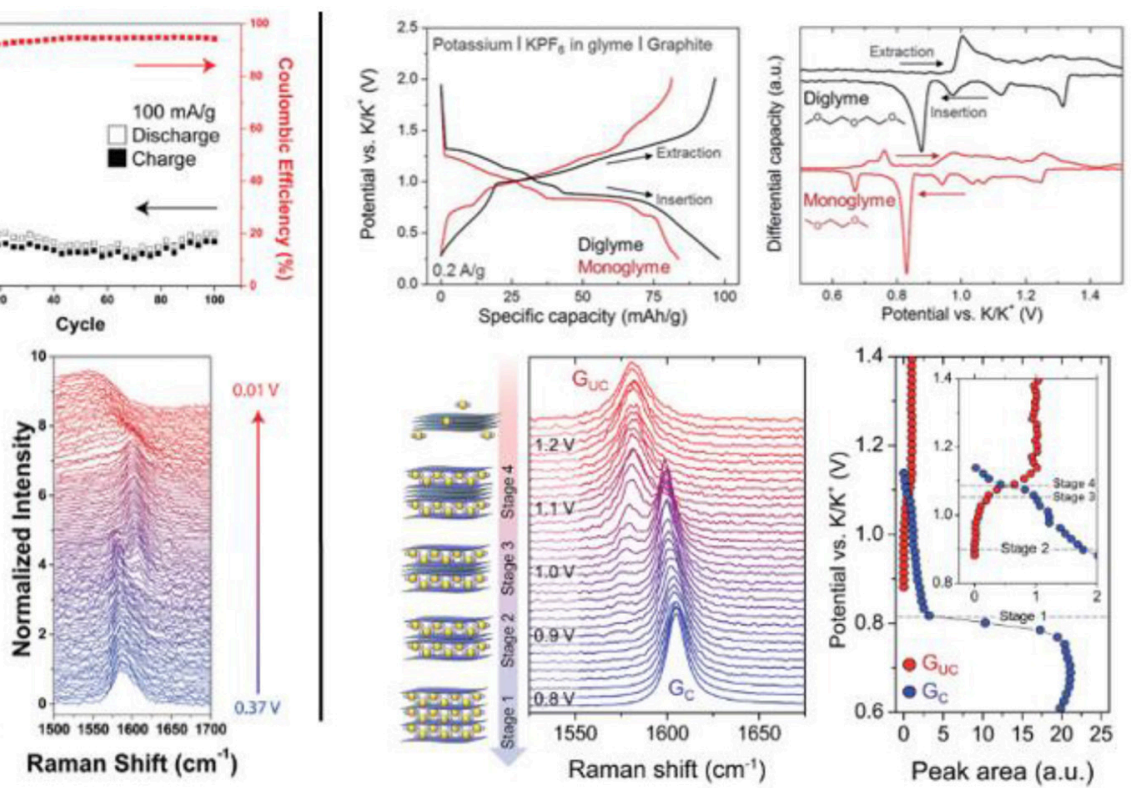

Regarding cycling performance, Komaba et al. highlighted the influence of the binder on the performance of graphite-based electrodes (Komaba et al., 2015). Higher coulombic efficiencies are obtained with PA-Na and CMC-Na binders than with 
PVdF. The electrolyte solvent also has a strong influence, in agreement with the previously discussed comparison between carbonates and ether based solvents. Focusing on carbonates, Zhao et al. showed that an improved capacity retention of 220 and $200 \mathrm{mAh} / \mathrm{g}$ can be obtained at $20 \mathrm{~mA} / \mathrm{g}$ with EC/PC and EC/DEC mix, respectively, while with a EC/DMC mix the capacity decreases continuously (Zhao J. et al., 2016). Polynanocrystalline graphite synthesized by CVD showed a low coulombic efficiency of 54\% during the first cycle (compared to $78 \%$ for graphite) but better capacity retention, attributed to the presence of disordered nano-domains allowing the preservation of the structural integrity of the material upon the successive $\mathrm{K}^{+}$insertion/desinsertion (Xing et al., 2017). In a recent study, Hui et al. proposed that faster intercalation of $\mathrm{K}^{+}$into graphitic materials can be achieved with a preconditioning $\mathrm{Li}^{+}$based SEI layer (Hui et al., 2018). The relative low rate capability of graphite prompted the investigation of other carbonaceous materials. Among them, amorphous ordered mesoporous carbon (OMC) presents two interesting aspects for $\mathrm{K}$ ion storage: a larger interlayer spacing and more edges and defects than graphite, suitable for the intercalation and the adsorption of $\mathrm{K}^{+}$ ions, respectively (Wang W. et al., 2018). Thereby, this carbon exhibited higher reversible capacity than graphite during the first cycles, which was maintained at $257 \mathrm{mAh} / \mathrm{g}$ after 100 cycles at a current density of $50 \mathrm{~mA} / \mathrm{g}$.

Among the other carbonaceous materials investigated as possible anode materials for $\mathrm{KIB}, \mathrm{CNT}$ appear as promising by virtue of the interconnected conductive network that they form which also avoid the addition of dead volume materials such as binder and conductive additive. Nitrogen-doped cup-stacked CNT mats prepared by CVD exhibit a reversible capacity of $236 \mathrm{mAh} / \mathrm{g}$ after 100 cycles at $20 \mathrm{~mA} / \mathrm{g}$ whereas multiwall CNT mats do not intercalate $\mathrm{K}^{+}$ions reversibly (Zhao et al., 2018). Nitrogen-doped CNT prepared by pyrolysis of a metal organic framework delivered $255 \mathrm{mAh} / \mathrm{g}$ at $50 \mathrm{~mA} / \mathrm{g}$ after 300 cycles and a superior rate capability with $100 \mathrm{mAh} / \mathrm{g}$ at $2 \mathrm{~A} / \mathrm{g}$ with $\mathrm{KPF}_{6}(0.8 \mathrm{M})$ EC/DEC electrolyte (Xiong et al., 2018a). Wang et al. reported a detailed study of hierarchical CNT sponge with modulated bulk densities from 8 to $21 \mathrm{mg} / \mathrm{cm}^{3}$ and showed that the less dense CNT presenting the higher macropore volume and the higher specific capacity (Wang Y. et al., 2018).

Changing morphology, CNF have been also extensively investigated. CNF prepared by electrospinning showed high cycling stability sustaining $210 \mathrm{mAh} / \mathrm{g}$ over 1,200 cycles at $200 \mathrm{~mA} / \mathrm{g}$ with $\mathrm{KPF}_{6}(0.8 \mathrm{M})$ in EC/DEC electrolyte (Zhao et al., 2017). N-doped CNF synthesized by carbonization under $\mathrm{N}_{2}$ atmosphere of polypyrrole precursor displayed similar performance with good capacity retention and high rate capability (Xu et al., 2018). A quantitative analysis of the storage properties of $\mathrm{N}-\mathrm{CNF}$ carbonized at different temperature from 650 to $1,100^{\circ} \mathrm{C}$ revealed that low temperatures induce $\mathrm{K}^{+}$ adsorption/desorption process ascribed to capacitive behavior whereas higher carbonization temperatures lead to $\mathrm{K}^{+}$faradic insertion/extraction processes. This was well described by Lin et al. using operando Raman spectroscopy on CNF carbonized at $650,1,250$, and $2,800^{\circ} \mathrm{C}$ (Lin et al., 2019). They showed that the presence of huge $\mathrm{N}$-induced defects or oxygenated functional groups using low temperature carbonization led to capacitive storage behavior at a potential higher than $1 \mathrm{~V}$. In the other side, $\mathrm{CNF}$ carbonized at $2,800^{\circ} \mathrm{C}$ showed faradic behavior at low potential and in situ Raman observations revealed the staging process on the graphene layers with the formation of $\mathrm{KC}_{24}$ and $\mathrm{KC}_{8}$ (Figure 3). The positive effect of $\mathrm{N}$-doping on graphene layers was previously demonstrated by Pint et al. through a study dedicated to manifold graphenes (Share et al., 2016b). For all the above-mentioned studies, the low coulombic efficiency during the first cycles due to the high specific area leading to strong electrolyte decomposition, as well as the shape of the potential profiles with progressive slope, remain a hurdle for industrial applications.

The performance of hard carbons, the renowned negative electrode in NIB (Irisarri et al., 2015), were also investigated in KIB. In a detailed study, Jian et al. compared the electrochemical reaction of $\mathrm{Na}^{+}$and $\mathrm{K}^{+}$with hard carbon microspheres electrodes prepared by pyrolysis of sucrose (Jian et al., 2016). The average potential plateau is slightly larger and the polarization higher with potassium than with sodium. However, better rate capability and capacity retention were obtained for potassium with $216 \mathrm{mAh} / \mathrm{g}$ after 100 cycles at $\mathrm{C} / 10$ rate with $\mathrm{KPF}_{6}$ $(0.8 \mathrm{M})$ in EC/DEC electrolyte. A comparative work of the carbon hardness was done by Ji et al. using hard carbons, soft carbons, and mixed composites of them in order to identify the main characteristics of non-graphitic carbon for potassium storage (Jian et al., 2017). Their electrochemical evaluation showed that the mixed composite exhibit the best performance combining good cycling stability and high rate capability of soft and hard carbons, respectively. The heat pre-treatment of saccharide-derived hard carbons before carbonization seems to be a key point for obtaining a molecular sieve-like framework structure formed by cross-linked turbostratic nanodomains which remains stable upon potassiation, and is therefore responsible of the good cycle life of the composite. With optimized synthesis parameters and PA-Na binder, Yamamoto et al. obtained a reversible capacity of $290 \mathrm{mAh} / \mathrm{g}$ during 50 cycles at $25 \mathrm{~mA} / \mathrm{g}$ with $\mathrm{KFSI}(1 \mathrm{M})$ in EC/DEC electrolyte (Yamamoto et al., 2018).

To conclude, a large range of carbonaceous materials have been studied as potential negative electrodes for KIB. Graphitic compounds can reversibly intercalate potassium ions at low potential following a staging process until the formation of $\mathrm{KC}_{8}$ with a theoretical capacity of $279 \mathrm{mAh} / \mathrm{g}$ but they present a relatively low rate capability. Porous carbons with high specific area such as CNF or CNT are characterized by capacitive behavior with adsorption/desorption of $\mathrm{K}^{+}$inside the porous structure, showing higher working potential and better capacity retentions and rate capabilities than graphite. The synthesis of materials with taylored structures combining the advantages of graphitic compounds and porous carbons might allow the development of more performing negative electrodes for KIB. 


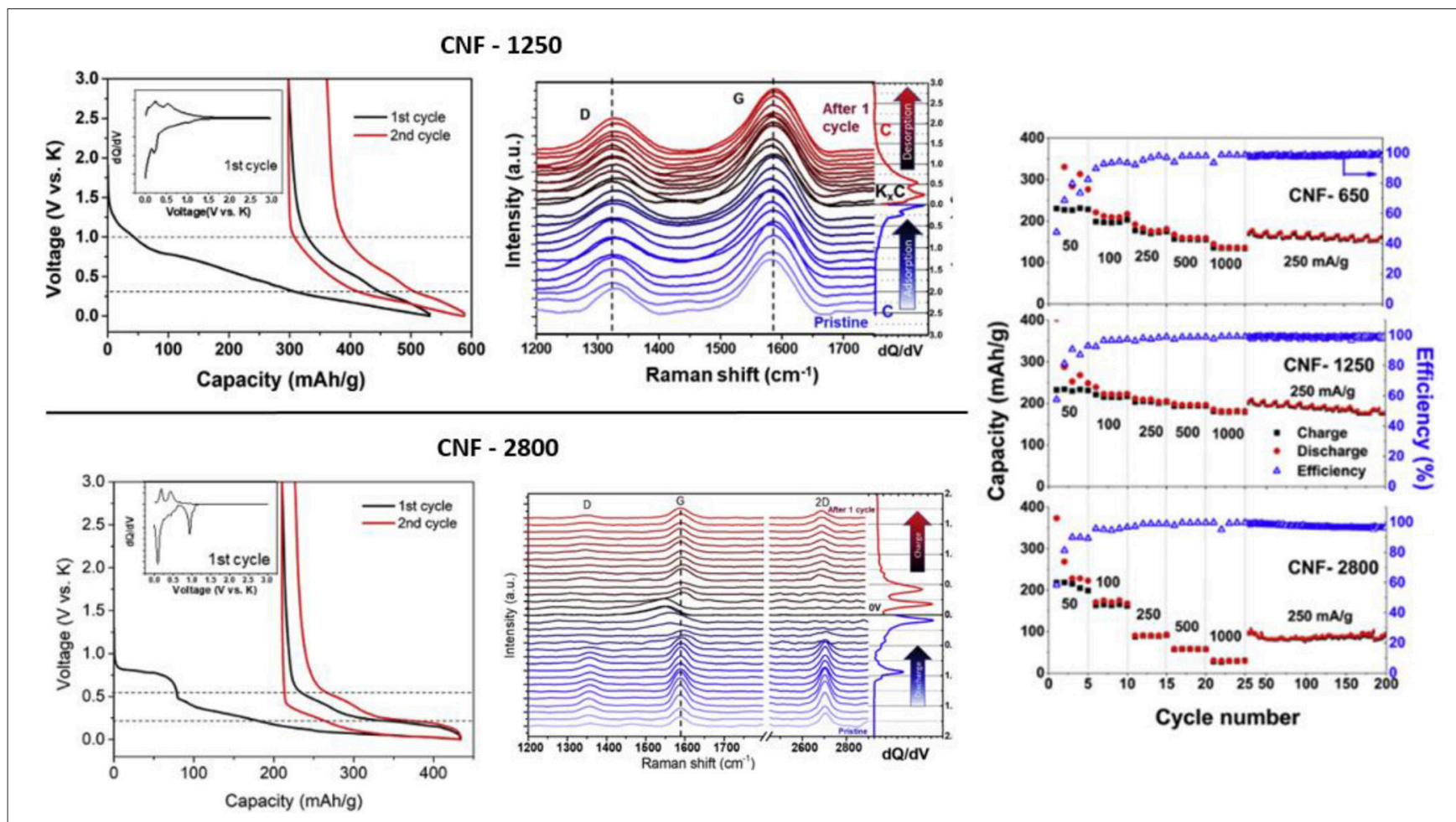

FIGURE 3 | Left, potential profile at $25 \mathrm{~mA} / \mathrm{g}$ and in situ Raman spectra of CNF annealed at $1,250^{\circ} \mathrm{C}$ (top) and CNF annealed at $2,800^{\circ} \mathrm{C}$ (bottom). Right, rate capability of CNF electrodes. Adapted from Lin et al. (2019) with permission from Elsevier.

\section{INSERTION-TYPE ELECTRODES}

\section{Titanium-Based Compounds}

Besides graphite and carbonaceous materials, most inorganic insertion-type materials investigated for their potential application as negative electrodes in KIB are based on the $\mathrm{Ti}^{3+} / \mathrm{Ti}^{4+}$ redox couple. Representative studies on the electrochemical properties of titanium oxides, phosphates and carbides are resumed in the following paragraphs.

Electrochemical insertion of lithium and sodium into titanium dioxides polymorphs have been intensively studied in the past especially as model electrode materials. More interestingly in terms of cycling performance, alkali titanium oxides, such as the spinel $\mathrm{Li}_{4} \mathrm{Ti}_{5} \mathrm{O}_{12}$ or the monoclinic $\mathrm{Na}_{2} \mathrm{Ti}_{3} \mathrm{O}_{7}$, combine low-cost synthesis and non-toxicity, and $\mathrm{Li}_{4} \mathrm{Ti}_{5} \mathrm{O}_{12}$ is nowadays in the spotlight of battery industry. In order to bypass the low electronic conductivity of $\mathrm{Na}_{2} \mathrm{Ti}_{3} \mathrm{O}_{7}$, Li et al. produced hydrogenated nanowires grown on $\mathrm{N}$-doped carbon sponge, and the resulting composite shows early-stage capacities of $108 \mathrm{mAh} / \mathrm{g}$ at 100 $\mathrm{mA} / \mathrm{g}$, and good capacity retention, with $\mathrm{KPF}_{6}(1 \mathrm{M})$ in EC:DEC electrolyte (Li et al., 2018).

The potassium analogs $\left(\mathrm{K}_{2} \mathrm{Ti}_{4} \mathrm{O}_{9}, \mathrm{~K}_{2} \mathrm{Ti}_{6} \mathrm{O}_{13}\right.$, and $\left.\mathrm{K}_{2} \mathrm{Ti}_{8} \mathrm{O}_{17}\right)$ have been also recently investigated (Figure 4). In 2016, Kishore et al. prepared micrometric-sized $\mathrm{K}_{2} \mathrm{Ti}_{4} \mathrm{O}_{9}$ by solid-state route and reported an initial capacity of $97 \mathrm{mAh} / \mathrm{g}$ at $30 \mathrm{mAh} / \mathrm{g}$ with $\mathrm{KPF}_{6}(1 \mathrm{M})$ in EC:PC (Kishore et al., 2016). Good capacity retention was observed at low rates, but rapid fading occurs with increasing current densities. As for other insertion-type materials, particles downsizing is expected to improve the ionic diffusion and thus boost the performance. Indeed, $\mathrm{K}_{2} \mathrm{Ti}_{4} \mathrm{O}_{9}$ nanoribbons made from acid-leached $\mathrm{Ti}_{3} \mathrm{C}_{2}$ (MXene) obtained through an hydrothermal route exhibit higher capacity even at high current rates as well as longer cycling life, using a $\mathrm{KPF}_{6}(1 \mathrm{M})$ in diglyme electrolyte (Dong et al., 2017) (Figure 4). The preparation of $\mathrm{C}-\mathrm{K}_{2} \mathrm{Ti}_{4} \mathrm{O}_{9}$ nanocomposites by conversion of $\mathrm{Ti}_{2} \mathrm{AlC}$ is also a possible alternative, however the resulting material was only investigated as LIB electrode (Liu et al., 2019). In the same direction, nanostructured $\mathrm{K}_{2} \mathrm{Ti}_{8} \mathrm{O}_{17}$ or $\mathrm{K}_{2} \mathrm{Ti}_{6} \mathrm{O}_{13}$ were prepared by hydrothermal processes. Using $\mathrm{KPF}_{6}$ $(0.8 \mathrm{M})$ in EC:DEC electrolyte, composite electrodes made of acanthosphere-like $\mathrm{K}_{2} \mathrm{Ti}_{8} \mathrm{O}_{17}$ nanorods exhibit at $20 \mathrm{~mA} / \mathrm{g}$ a first discharge capacity exceeding $180 \mathrm{mAh} / \mathrm{g}$. In spite of an important irreversible capacity in first cycle, this materials maintains a stable capacity exceeding $115 \mathrm{mAh} / \mathrm{g}$ for 50 cycles at low rates; this value, however, fades rapidly when the rate is increased (Han et al., 2016b). In a similar approach, $\mathrm{K}_{2} \mathrm{Ti}_{6} \mathrm{O}_{13}$ nanorods structured in microscaffolds were been prepared through an hydrothermal process under alkaline conditions. At $50 \mathrm{~mA} / \mathrm{g}$, the initial discharge capacity nears $300 \mathrm{mAh} / \mathrm{g}$ with $\mathrm{KPF}_{6}(0.8 \mathrm{M})$ in PC (with 5 vol.\% of FEC additive) electrolyte. After an important irreversible loss during the subsequent charge, the cycling capacity remains stable about $90 \mathrm{mAh} / \mathrm{g}$ (Dong et al., 2018). For all these oxides, a low coulombic efficiency attributed to the possible formation of SEI or to a significant trapping of potassium ions into the layered structure, is observed.

Polyanionic compounds are widely investigated as electrode materials for LIB and NIB as they usually shows very opened framework that ease the ionic diffusion. Moreover, 

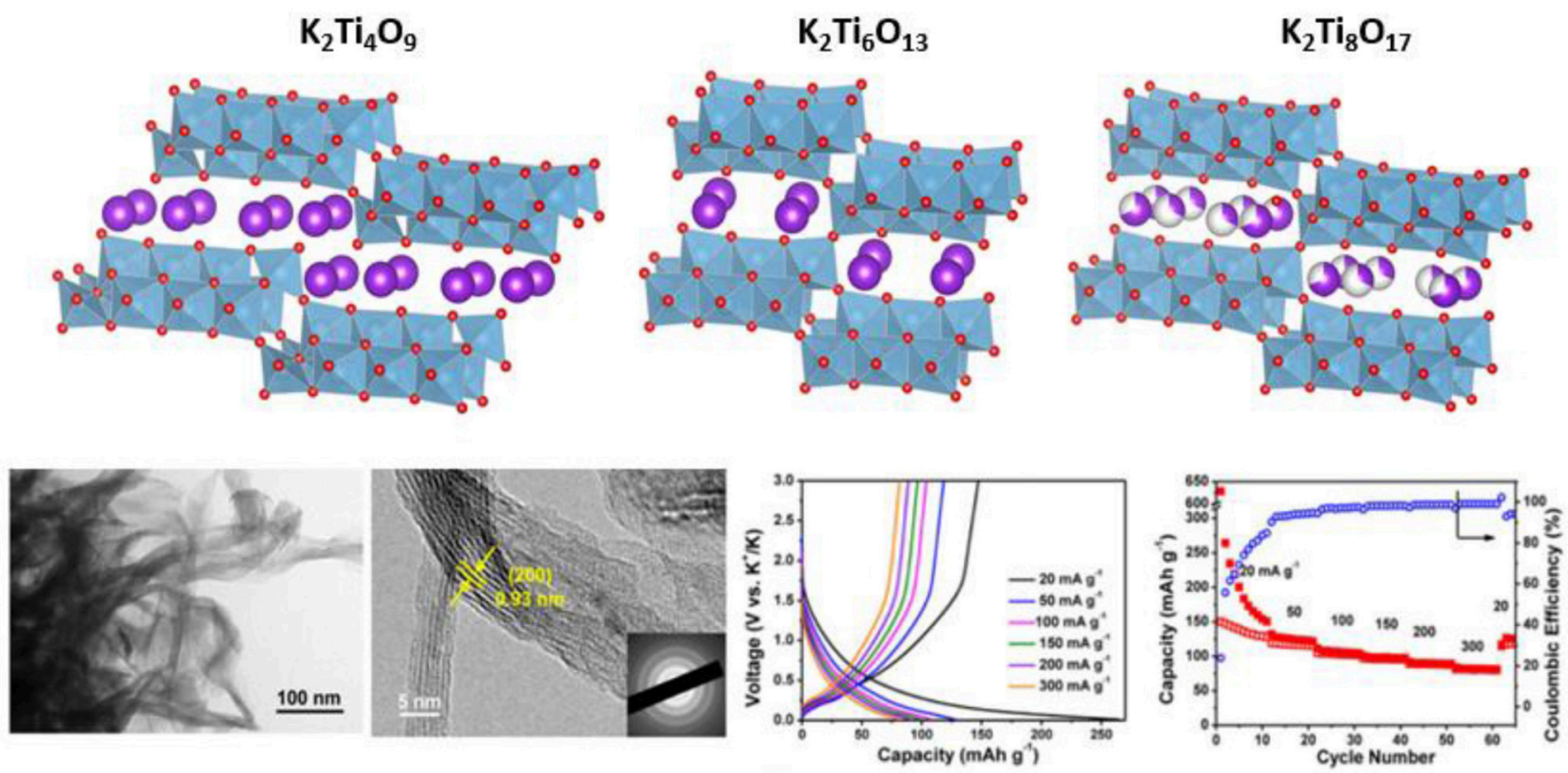

FIGURE 4 | Top, crystal structures of $\mathrm{K}_{2} \mathrm{Ti}_{4} \mathrm{O}_{9}, \mathrm{~K}_{2} \mathrm{Ti}_{6} \mathrm{O}_{13}$, and $\mathrm{K}_{2} \mathrm{Ti}_{8} \mathrm{O}_{17}$ (from left to right) showing the layered organization with triplet of edge-shared $\mathrm{TiO}_{6}$ octahedra chains and potassium ions in the interslab spaces. Bottom, TEM and HRTEM of $\mathrm{Ti}_{3} \mathrm{C}_{2}$-derived $\mathrm{K}_{2} \mathrm{Ti}_{4} \mathrm{O}_{9}$ nanoribbons and corresponding electrochemical performance. Adapted with permission from Dong et al. (2017) Copyright (2017) American Chemical Society.

chemical substitution, either of the transition element or of the ligand enable the tuning and sometimes the enhancement of the electrochemical properties (Messinger et al., 2015). Consequently, K-containing polyanionic compounds might also be interesting electrodes for KIB. While lot of compositions are suitable for the positive electrode side (Hosaka et al., 2019), so far only NASICON-type $\mathrm{KTi}_{2}\left(\mathrm{PO}_{4}\right)_{3}$ has been reported to serve at the negative electrode. To balance the poor conductivity and access interesting electrochemical performance, surface engineering appears necessary. In 2016, Han et al. evaluated nanocubic $\mathrm{KTi}_{2}\left(\mathrm{PO}_{4}\right)_{3}$ obtained by hydrothermal route and carbon-coated $\mathrm{KTi}_{2}\left(\mathrm{PO}_{4}\right)_{3}$ prepared by cane sugar-assisted method (Han et al., 2016a). In both cases, a discharge potential plateau at $1.7 \mathrm{~V}$ is observed after the first cycle, whereas the charge profile is slopier (Figure 5). Without carbon coating, the capacity of $\mathrm{KTi}_{2}\left(\mathrm{PO}_{4}\right)_{3}$ at $\mathrm{C} / 2$ current rate with $\mathrm{KPF}_{6}(0.8 \mathrm{M})$ in EC:DEC electrolyte rapidly decreases after the initial discharge capacity around $75 \mathrm{mAh} / \mathrm{g}$, Spheroidal $\mathrm{KTi}_{2}\left(\mathrm{PO}_{4}\right)_{3} @ \mathrm{C}$ nanocomposites prepared by electrospray take advantage of the intrinsic carbon network and offer sufficient porosity for an efficient electrolyte impregnation. Consequently, the electrochemical performance is enhanced, with high reversible capacity of $293 \mathrm{mAh} / \mathrm{g}$ at $20 \mathrm{~mA} / \mathrm{g}$ and very good rate capability $(133 \mathrm{mAh} / \mathrm{g}$ at $1 \mathrm{~A} / \mathrm{g})$ (Wei et al., 2018). Hierarchical $\mathrm{Ca}_{0.5} \mathrm{Ti}_{2}\left(\mathrm{PO}_{4}\right)_{3} @ \mathrm{C}$ microspheres were also prepared by electrospray. In this case, the divalent calcium cations induces vacancies in the pristine materials that could enhance ionic diffusion (Figure 5). The electrochemical performance is interesting, with a stabilized capacity close to 250 $\mathrm{mAh} / \mathrm{g}$ at $50 \mathrm{mAh} / \mathrm{g}$ (Zhang Z. et al., 2018).

The electrochemical insertion of potassium was also tested in MXene compounds. These early transition metal carbides or carbonitrides offer interslab spacing in 2D morphologies allowing fast ionic diffusion. MXenes are usually obtained by the leaching of the A layers in pristine phase $M_{n+1} A X_{n}$. It results in the chemical composition $M_{n+1} X_{n}$, or $M_{n+1} X_{n} T x$ if ones includes anionic termination groups coming from the leaching step. Theoretical simulation of potassium insertion into $\mathrm{Ti}_{3} \mathrm{C}_{2}$ or O-terminated $\mathrm{Ti}_{2} \mathrm{CO}_{2}$ MXenes provides high capacities of 192 and $264 \mathrm{mAh} / \mathrm{g}$, respectively (Er et al., 2014; Xie et al., 2014). $\mathrm{Ti}_{3} \mathrm{C}_{2} \mathrm{~T}_{\mathrm{x}}(\mathrm{T}=\mathrm{O}$, $\mathrm{F}$, and/or $\mathrm{OH}$ ) was evaluated as electrode material, providing a first discharge capacity of $260 \mathrm{mAh} / \mathrm{g}$ (in $\mathrm{KPF}_{6}(1 \mathrm{M}$ ) in EC:PC electrolyte) as predicted. While the subsequent charge is still interesting $(146 \mathrm{mAh} / \mathrm{g})$, a continuous capacity fading is observed upon cycling (down to $45 \mathrm{mAh} / \mathrm{g}$ after 120 cycles). Tridimensional porous alkalized $\mathrm{Ti}_{3} \mathrm{C}_{2}$ nanoribbons with an expanded interslab space were easily obtained from $\mathrm{Ti}_{3} \mathrm{C}_{2}$ in aqueous $\mathrm{KOH}$ by Lian et al. These materials exhibit a capacity retention of $42 \mathrm{mAh} / \mathrm{g}$ at $200 \mathrm{mAh} / \mathrm{g}$ after 500 cycles (Lian et al., 2017).

In summary, although good discharge capacities are usually observed for titanium-based insertion anode materials, the subsequent irreversible and rapid fading dramatically lowers the overall performance. The insertion of a large amount of potassium ions in rigid crystalline structures does not seem straightforward, and only limited capacities are obtained. Moreover, capacity fading is often observed at elevated current densities, most probably related to important kinetic limitations. It is interesting to note a kind of consensus in the use of the electrolyte when studying such insertion-type materials. Indeed, all the above mentioned works mentioned $\mathrm{KPF}_{6}$-based electrolytes. As it 

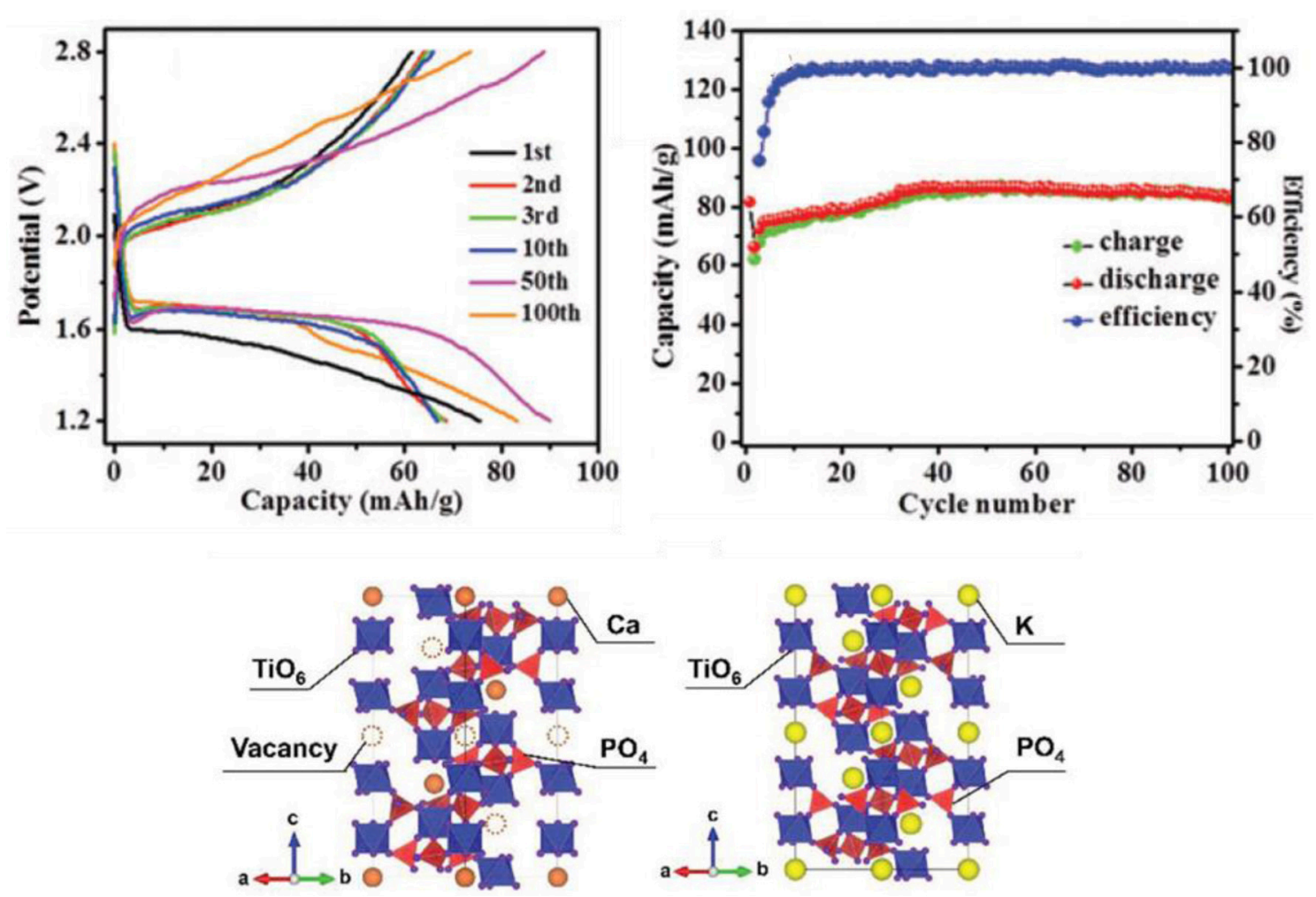

FIGURE 5 | On top, electrochemical performance of C-coated $\mathrm{KTi}_{2}\left(\mathrm{PO}_{4}\right)_{3}$; below, crystallographic structure of $\mathrm{Ca}_{0.5} \mathrm{Ti}_{2}\left(\mathrm{PO}_{4}\right)_{3}$ showing the cationic vacancies which promotes the potassium ion diffusion. Reproduced and adapted from Han et al. (2016a) with permission from the Royal Society of Chemistry, and with permission from Zhang Z. et al. (2018). Copyright (2018) WILEY-VCH Verlag GmbH \& Co. KGaA, Weinheim.

is shown with other electrode materials, the electrolyte is expected to influence the cycling performance. Therefore, revisiting these titanium-based materials with other electrolyte salts and formulations might lead to enhanced electrochemical properties.

\section{Other Insertion-Type Electrode Materials}

Electrodes based on vanadates, such as many different $\mathrm{V}_{2} \mathrm{O}_{5}$ polymorphs have been intensively investigated for their alkali insertion properties. Potassium vanadium oxides gathers a wide range of compounds, which are mainly proposed as positive electrode materials for LIB. Interestingly, Liu et al. revisited hydrothermally-obtained $\mathrm{K}_{0.23} \mathrm{~V}_{2} \mathrm{O}_{5}$ and evidenced the very lowpotential of the electrochemical insertion of potassium (Liu et al., 2018). The very high first discharge capacity of $800 \mathrm{mAh} / \mathrm{g}$ (caused by significant side reactions) is not maintained upon cycling, and a stable capacity of $100 \mathrm{mAh} / \mathrm{g}$ at $20 \mathrm{~mA} / \mathrm{g}$ with $\mathrm{KPF}_{6}$ $(0.8 \mathrm{M})$ in an EC:DEC as electrolyte is rather obtained.

Layered transition metal dichalcogenides exhibit a lamellar structure with open diffusion planes. Although potassium chemical insertion into layered $\mathrm{MoS}_{2}$ has been studied for decades to access unusual physical properties such as superconductivity, electrochemical insertion was reported only recently. Starting from commercial $\mathrm{MoS}_{2}$ and using a simple electrode formulation, a stable capacity of $65 \mathrm{mAh} / \mathrm{g}$ was obtained at current density of $20 \mathrm{~mA} / \mathrm{g}$ (Ren et al., 2017). Even though the corresponding redox potential is quite high for a negative electrode material $(1.2-1.5 \mathrm{~V})$, the abundance of $\mathrm{MoS}_{2}$ could make it a material of choice for sustainable largescale applications.

\section{ALLOYING AND CONVERSION ELECTRODES}

The properties of insertion-type electrode materials presented in the previous sections clearly demonstrate that open crystallographic structures might not be able to stabilize the reversible insertion of potassium ions over long periods of time. With conversion and alloying-type materials, conversely, there is no problem of sluggish potassium ions diffusion in the crystalline structure as the electrochemical process completely reshapes the pristine material and forms new potassium-containing species through phase transitions. In this section, intermetallic compounds and conversion type materials based on $p$-block elements will be discussed as possible negative electrode materials. As in the case of lithium and sodium, also with potassium the formation of such phases correspond to high theoretical capacities with concomitant high volume expansions that need to be tackled down by electrode engineering (Sultana et al., 2018). In some cases, a composite 

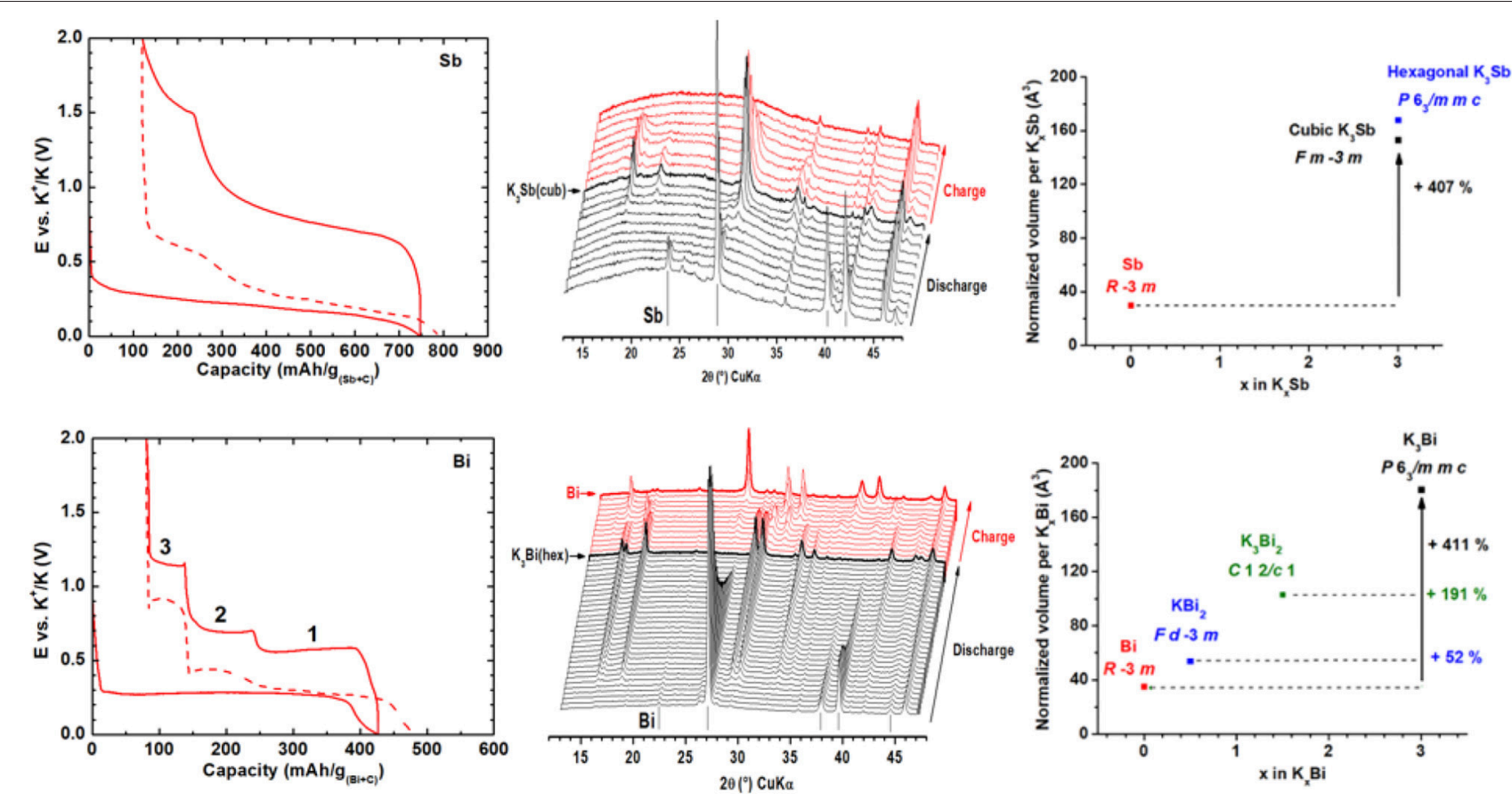

FIGURE 6 | Left, galvanostatic profiles of Sb (top) and Bi (bottom) electrode cycled at C/5 rate. Middle, operando XRD patterns recorded during the first cycle. Right, evolution of the normalized volume change upon potassiation. Reprinted with permission from Gabaudan et al. (2018a). Copyright (2018) American Chemical Society.

approach is used to tackle the expansion issue, combining the active elements with carbon which can also contribute to the capacity.

Among the alloying elements, antimony appears to be very interesting because of its low working potential vs. $\mathrm{K}^{+} / \mathrm{K}$ and its high theoretical capacity of $660 \mathrm{mAh} / \mathrm{g}$ corresponding to the formation of $\mathrm{K}_{3} \mathrm{Sb}$. In 2015, McCulloch et al. investigated a $\mathrm{Sb} / \mathrm{C}$ nanocomposite prepared by ball-milling and reached $600 \mathrm{mAh} / \mathrm{g}$ at $35 \mathrm{~mA} / \mathrm{g}$ with $\mathrm{KPF}_{6}(1 \mathrm{M})$ in EC:PC electrolyte (McCulloch et al., 2015). The formation of cubic $\mathrm{K}_{3} \mathrm{Sb}$ was shown by XRD. The overall electrochemical mechanism was later detailed by other groups. The formation of amorphous intermediates $\mathrm{K}_{\mathrm{X}} \mathrm{Sb}$ was proposed by operando $\mathrm{XRD}$, and the amorphous state of $\mathrm{Sb}$ after charge was confirmed by Raman spectroscopy, whereas our group also pointed out the formation of minor amounts of hexagonal $\mathrm{K}_{3} \mathrm{Sb}$ (Tzolov and Iliev, 1992; Gabaudan et al., 2018a; Han et al., 2018; Yi et al., 2018) (Figure 6). It is important to notice here that different kind of pristine particles were used in these papers, going from bulk $\mathrm{Sb}$ to nanoparticles confined in a porous carbon matrix, all leading to very similar electrochemical mechanisms. Moreover, the reaction mechanism of $\mathrm{Sb}$ with $\mathrm{K}$ is not yet fully understood due to the extensive amorphisation of the material during cycling, and several efforts have to be done in the future to identify the structural transformations which take place during cycling. This cannot be done without the use of powerful techniques probing the local environment around the $\mathrm{Sb}$ atoms such as XAS or PDF analysis, by comparing samples obtained by electrochemistry with references prepared via solid state chemistry as it was done in the past for Sb in NIB (Allan et al., 2016; Darwiche et al., 2018).

Similarly to antimony, bismuth can react with potassium to form $\mathrm{K}_{3} \mathrm{Bi}$, corresponding to a theoretical capacity of $385 \mathrm{mAh} / \mathrm{g}$. Whatever the nature of the Bi electrode and of the electrolyte, a single potential plateau is observed around $0.35 \mathrm{~V}$ under galvanostatic conditions during the first discharge suggesting a two-phase reaction. During the following sweeps, however, three flat plateaus can be detected between 0.5 and $1.3 \mathrm{~V}$, in line with three independent reaction steps. Very early, Zhang et al. proposed a reversible potassiation in two steps from $\mathrm{Bi}$ to $\mathrm{KBi}$ and then from $\mathrm{KBi}$ to $\mathrm{K}_{3} \mathrm{Bi}$ whereas Guo et al. suggested the formation of a $\mathrm{Bi}-\mathrm{K}$ solid solution process before a two-phase reaction between $\mathrm{K}_{5} \mathrm{Bi}_{4}$ and $\mathrm{K}_{3} \mathrm{Bi}$. Huang et al. corroborated experimental data with DFT calculations and showed the continuous formation of $\mathrm{K}_{3} \mathrm{Bi}$ during the first reduction and then a three-step process upon the oxidation leading successively to $\mathrm{K}_{3} \mathrm{Bi}_{2}$ and $\mathrm{KiB}_{2}$ and $\mathrm{Bi}$, discarding $\mathrm{K}_{5} \mathrm{Bi}_{4}$ and $\mathrm{KBi}$. The same mechanism was proposed by Lei et al. with Rietveld refinements of ex situ XRD patterns and by Gabaudan et al. in operando conditions (Figure 6). Tin is a well-known anode material in LIB and NIB, theoretically providing specific capacities of 991 and $847 \mathrm{mAh} / \mathrm{g}$ corresponding to the formation of $\mathrm{Li}_{22} \mathrm{Sn}_{5}$ and $\mathrm{Na}_{15} \mathrm{Sn}_{4}$, respectively. Moreover, tin is earth-abundant, low cost and non-toxic. In KIB, first principle DFT calculations suggested the formation of KSn as the most potassiated phase at the average potential of $0.5 \mathrm{~V}$ leading to a capacity of $226 \mathrm{mAh} / \mathrm{g}$ (Kim et al., 2018). In the first experimental study by Sultana et al. a $\mathrm{Sn} / \mathrm{C}$ composite prepared by ball-milling exhibited a 
first reversible capacity of $150 \mathrm{mAh} / \mathrm{g}$ (Sultana et al., 2016). The corresponding galvanostatic profile shows a single plateau during the discharge whereas several processes are observed (but not explained) upon charge. Wang et al. obtained similar features using Sn nanoparticles and identified the formation of KSn with both ex situ XRD and electron diffraction (Wang et al., 2017). Looking at the evolution of volume expansion by in situ TEM, they also suggested the formation of amorphous $\mathrm{K}_{4} \mathrm{Sn}_{9}$ as intermediate phase only during the discharge. More recently, in situ synchrotron XRD performed on CVD Sn film cycled at 0.1 $\mathrm{mV} / \mathrm{s}$ showed that $\mathrm{Sn}$ could also be directly converted into KSn (Ramireddy et al., 2017). The volume expansion resulting from the KSn formation is $180 \%$, which is relatively low compared to formation of $\mathrm{Li}_{22} \mathrm{Sn}_{5}$ (257\%) and $\mathrm{Na}_{15} \mathrm{Sn}_{4}$ (410\%) in LIB and NIB. Nevertheless, the potassiation of tin is also accompanied by many cracks inducing electrode pulverization and continuous electrolyte degradation with the exposition of fresh tin surfaces to electrolyte.

In parallel to the understanding of the electrochemical alloying mechanism, several strategies targeting the improvement of the cycling performance were proposed. In their seminal work, McCulloch et al. observed rapid capacity fading after few cycles with a $\mathrm{Sb} / \mathrm{C}$ nanocomposite. By reducing the potential window, they limited the volumetric expansion and stabilized a reversible capacity of $250 \mathrm{mAh} / \mathrm{g}$ for almost 50 cycles (McCulloch et al., 2015). The formulation of the composite material plays an important role on the cycling performance as it was reported for ball milling Sb/C (Sultana et al., 2019). More carbon allowed to improve the cycling stability but reduced capacities are obtained taking into account the mass of composite for the capacity calculation. The choice of electrolyte is also a key parameter to promote the performance. With Sb-based electrodes, the use of KFSI salt instead of $\mathrm{KPF}_{6}$ in a mix of EC:DEC allowed obtaining a better SEI stability and thus higher coulombic efficiencies and capacity retentions (Madec et al., 2018; Zhang Q. et al., 2018). Enhanced performance can also be obtained by using salt concentrated electrolytes as it was reported by Liu et al. with KFSI (3M) in DME giving for an Sb/C composite electrode a capacity of $200 \mathrm{mAh} / \mathrm{g}$ after 800 cycles at 1 A/g (Liu Q. et al., 2018). Moving to bismuth-based electrodes, it is also interesting to notice that carbonate-based electrolytes seem not appropriated as they lead to rapid capacity fading. Moreover, it is not well understood why the plateaus corresponding to the phase transitions $\mathrm{KBi}_{2}-\mathrm{Bi}$ and $\mathrm{K}_{3} \mathrm{Bi}_{2}-\mathrm{KBi}_{2}$ are not preserved upon cycling using carbonate-based electrolytes, whereas they are conserved using ethers as electrolyte solvents. The choice of the potassium salt is also crucial: better coulombic efficiencies are reported with both KFSI salt instead of $\mathrm{KPF}_{6}$, and ether-based electrolytes, including monoglyme or diglyme, instead of carbonate based electrolytes. The salt concentration plays also a significant role on the electrode performance as it was shown by Zhang et al. with KTFSI salt in diglyme giving better performance for a Bi@C composite electrode with $5 \mathrm{M}$ salt concentrated electrolyte (Zhang R. et al., 2018). Recently, outstanding capacity retention of $550 \mathrm{mAh} / \mathrm{g}$ after 100 cycles was obtained for a $\mathrm{Sb} / \mathrm{C}$ composite synthesized by electrospray assisted strategy cycled with KTFSI $(4 \mathrm{M})$ in EC/DEC mix
(Zheng et al., 2019). Looking at the influence of the solvent, it was reported by Chen et al. that monoglyme molecules undergo a specific chemical adsorption at the surface of $\mathrm{Bi}$ electrodes leading to a stable SEI and better performance compared to PC-based electrolytes (Lei et al., 2018). Thereby, they obtained a capacity of $320 \mathrm{mAh} / \mathrm{g}$ at $2 \mathrm{C}(800 \mathrm{~mA} / \mathrm{g})$ after 300 cycles with a DME-based electrolyte in $\mathrm{K} / \mathrm{Bi}$ half-cell configuration. A Bi/rGO nanocomposite synthesized via a room temperature solution route sustained a capacity of $290 \mathrm{mAh} / \mathrm{g}$ after 50 cycles at 50 $\mathrm{mA} / \mathrm{g}$ (Zhang Q. et al., 2018). Same trends were observed for tin-based electrodes. The use of the KFSI salt instead of $\mathrm{KPF}_{6}$ in EC:DEC, as well as a limited potential window between 0.01 and $1.2 \mathrm{~V}$, led to better cycling performance (Ramireddy et al., 2017; Zhang Q. et al., 2018).

Other alloying type materials such as $\mathrm{Si}, \mathrm{Ge}$, and $\mathrm{Pb}$ catch minor attention for the time being. These elements can react with only one potassium leading however to interesting theoretical capacities of 954,369 , and $129 \mathrm{mAh} / \mathrm{g}$, respectively. Regarding silicon, Sultana et al. did not obtained a reliable evidence of the electrochemical potassiation of a Si/graphene electrode in contrast with the predicted formation of KSi alloy suggested by Ceder (Kim et al., 2018; Sultana et al., 2018). The only reported electrochemical activity of silicon can be found in the work of Komaba et al., who used a Si/graphite composite formulated with PA-Na binder which exhibited a reversible capacity of 510 $\mathrm{mAh} / \mathrm{g}$ (Kubota et al., 2018). The activity of Ge in KIB, on the other hand, was only reported by Guo et al. with the use of $\mathrm{GeP}_{5}$ leading to the formation of KGe (Zhang et al., 2018a). Lead presents a relatively low theoretical capacity $(127 \mathrm{mAh} / \mathrm{g})$. The electrochemical alloying pathway was carefully followed by operando $\mathrm{XRD}$, showing a three-step process during the discharge with $\mathrm{K}_{10} \mathrm{~Pb}_{48}$ and $\mathrm{K}_{4} \mathrm{~Pb}_{9}$ intermediates and $\mathrm{KPb}$ as the final product, whereas only $\mathrm{K}_{4} \mathrm{~Pb}_{9}$ is evidenced during charge before the recovery of $\mathrm{Pb}$ metal (Gabaudan et al., 2018b).

Among $p$-block elements, phosphorus appears as a very promising electrode material by virtue of its high abundance and of its very high theoretical capacity: $2,594 \mathrm{mAh} / \mathrm{g}$ are expected for the formation of $\mathrm{K}_{3} \mathrm{P}$. The K-P phase diagram presents the following range of alloys: $\mathrm{K}_{3} \mathrm{P}, \mathrm{K}_{4} \mathrm{P}_{3}, \mathrm{KP}, \mathrm{K}_{4} \mathrm{P}_{6}, \mathrm{~K}_{3} \mathrm{P}_{7}, \mathrm{~K}_{3} \mathrm{P}_{11}$, and $\mathrm{KP}_{15}$ might be observed during the electrochemical potassiation of phosphorus (Sangster, 2010). First principle calculations conducted by Ceder et al. showed that $\mathrm{KP}$ and $\mathrm{K}_{4} \mathrm{P}_{3}$ phases might be formed at the potential of 0.8 and $0.2 \mathrm{~V}$, respectively whereas $\mathrm{K}_{3} \mathrm{P}$ appeared to be unstable in their calculation (Kim et al., 2018). However, phosphorus suffers from both a low electrical conductivity and a substantial volume expansion as all alloying materials. The use of intermetallic compounds as well as nanostructuration in porous carbon frameworks are possible solutions to overcome these drawbacks. Combining phosphorous with other active elements, or looking for nanostructured architectures in porous conductive frameworks is mandatory to balance its low electrical conductivity. The first study of a phosphorus-containing compound was performed by Guo et al., using a $\mathrm{Sn}_{4} \mathrm{P}_{3} / \mathrm{C}$ composite which exhibited a capacity of 307 $\mathrm{mAh} / \mathrm{g}$ after 50 cycles at $50 \mathrm{~mA} / \mathrm{g}$, much better than both $\mathrm{P} / \mathrm{C}$ or Sn/C electrodes (Zhang W. et al., 2017) (Figure 7). The synthesis of $\mathrm{Sn}_{4} \mathrm{P}_{3}$ nanoparticles embedded into porous carbon fibers 

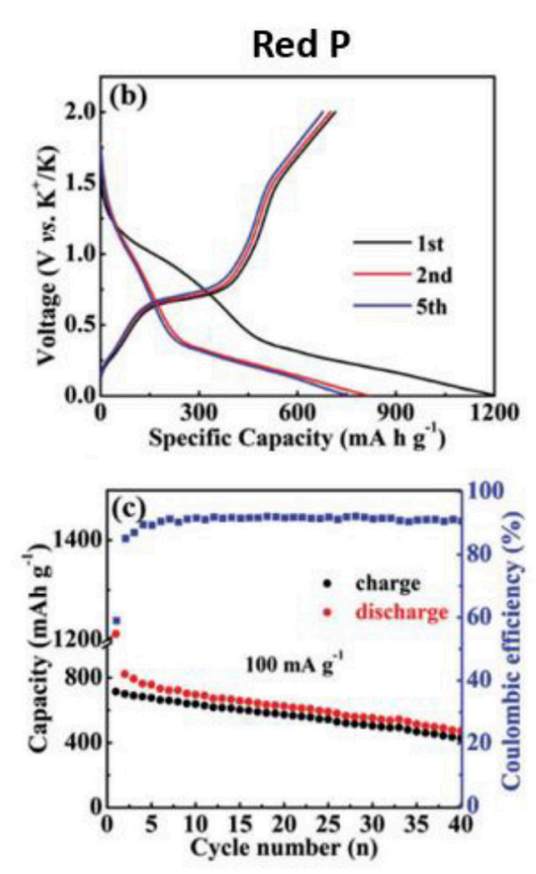
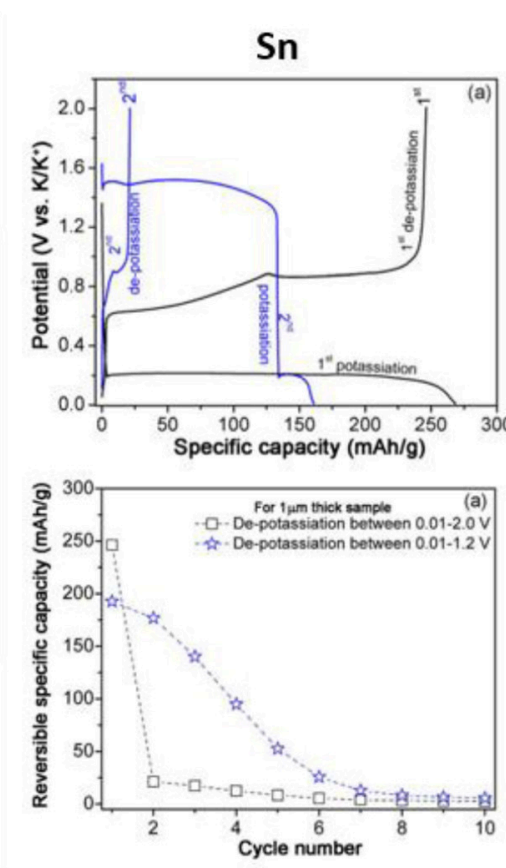
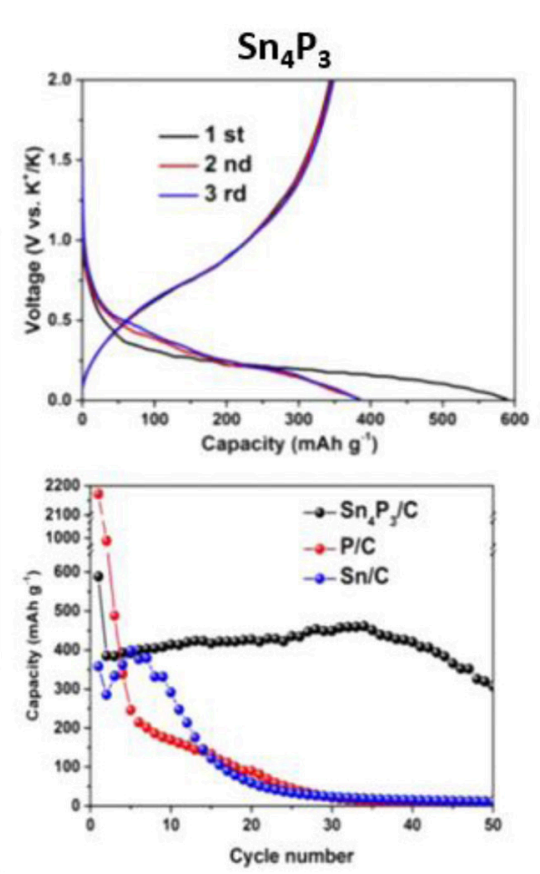

FIGURE 7 | Galvanostatic profiles and capacity retention of red P@CN composite (left), Sn electrode prepared by e-beam evaporation process (middle), and ball milled $\mathrm{Sn}_{4} \mathrm{P}_{3} / \mathrm{C}$ (right). Reprinted with permission from Zhang W. et al. (2017) Copyright (2018) American Chemical Society, from Xiong et al. (2018b). Copyright (2018) WILEY-VCH Verlag GmbH \& Co. KGaA, Weinheim, and from J. Electrochem. Soc., 164, 12360 (2017). Copyright 2017, The Electrochemical Society.

in addition to the substitution of $\mathrm{KPF}_{6}$ salt by KFSI allowed a significant improvement of the cycling performance (Zhang et al., 2018b). Following the $\mathrm{Sn}_{4} \mathrm{P}_{3}$ study, they looked at the potassiation of nanocrystalline $\mathrm{GeP}_{5}$ synthesized by ball milling which exhibited a reversible capacity of $495 \mathrm{mAh} / \mathrm{g}$ after 50 cycles at $50 \mathrm{~mA} / \mathrm{g}$ (Zhang et al., 2018a). FTIR measurements performed on $\mathrm{GeP}_{5}$ electrode after one cycle revealed the formation of homogeneous SEI layer with both KFSI and $\mathrm{KPF}_{6}$ in EC/DEC, while the use of $5 \%$ of FEC induced a non-uniform and thick SEI. The confinement of phosphorus into porous carbon host have been intensively studied in LIB with the purpose of increasing the electrical conductivity and buffering the volume change during the alloying process. The same methodology was also applied in KIB with the reported P/C ball-milled composites and P@CN, P@TBMC or P@rGO synthesized by vaporization/condensation route (Sultana et al., 2017a,b; Liu D. et al., 2018; Wang H. et al., 2018; Wu et al., 2018b; Xiong et al., 2018b) (Figure 7). Looking at the electrochemical behavior of these materials, the first discharge capacity never reached 2,596 $\mathrm{mAh} / \mathrm{g}$ as expected for the formation of $\mathrm{K}_{3} \mathrm{P}$, but rather capacities near $850 \mathrm{mAh} / \mathrm{g}$ expected for the formation of KP. In spite of this unexpected low capacity, promising cycling properties are observed for phosphorus: a capacity of $427 \mathrm{mAh} / \mathrm{g}$ is measured after 40 cycles at $100 \mathrm{~mA} / \mathrm{g}$ for red $\mathrm{P}$ nanoparticles embedded into $3 \mathrm{D}$ carbon nanosheet framework, whereas $366 \mathrm{mAh} / \mathrm{g}$ after 50 cycles at $100 \mathrm{~mA} / \mathrm{g}$ are obtained for red $\mathrm{P}$ vaporized and dispersed into reduced graphene oxide (Wang H. et al., 2018; Xiong et al., 2018b).

A few conversion materials were also reported as possible negative electrode for $\mathrm{KIB}$ such as $\mathrm{Co}_{3} \mathrm{O}_{4}-\mathrm{Fe}_{2} \mathrm{O}_{3}$, tin oxides or antimony and tin sulfides (Lakshmi et al., 2017; Sultana et al., 2017b; Liu Y. et al., 2018; Shimizu et al., 2018). Shimizu et al. reported the electrochemical activity of $\mathrm{SnO}$, which is irreversibly converted into tin nanoparticles embedded in a stable matrix of $\mathrm{K}_{2} \mathrm{O}$. This matrix hinders the aggregation of the tin nanoparticles, which then undergo alloying reaction with K (Shimizu et al., 2018). Interestingly, SnO exhibits a discharge capacity around $200 \mathrm{mAh} / \mathrm{g}$ during 30 cycles, whereas $\mathrm{SnO}_{2}$ appears to be inactive. In the studies of sulfide systems, nanocrystalline particles of antimony and tin sulfides were dispersed onto graphene frameworks in order to increase the electrical conductivity and minimize the volume variation upon cycling. As a consequence, few-layered antimony sulfide/carbon sheets showed promising performance combining successively the intercalation mechanism of $\mathrm{K}^{+}$between carbon sheets with a conversion mechanism of the sulfur with the formation of $\mathrm{K}_{2} \mathrm{~S}_{3}$ and an alloying reaction for the $\mathrm{Sb}$ converted into $\mathrm{K}_{3} \mathrm{Sb}$ (Liu Y. et al., 2018).

To summarize the results obtained with alloying materials, the theoretical capacities of the composite electrodes are easily reached during the first cycles but then decrease quickly over the first tens cycles. For the time being, the use of conventional electrolyte additives such as FEC or VC have not proven their efficiency to improve the cycling stability. Many efforts should be devoted to electrolyte formulation (salts, solvent, and additives) as well as to electrode formulation with efficient binders in order to improve the performance of alloying materials. The understanding of the electrochemical mechanisms also needs to be further deepened, considering that it is not basically a 
translation of those observed for the same materials in LIBand NIB.

\section{ORGANIC COMPOUNDS}

Organic materials are more and more targeted as effective electrode materials in LIB and NIB because they are low-cost and environment friendly, but also for their good cyclability. Focusing on the potassium electrochemical storage, the Van der Waals forces between the organic molecules lead to lower barrier energy and enable the formation of more free space to insert big metal ions. Most anode materials reported so far stem from the terephthalate structure.

In 2009, terephtalate compounds were highlighted as attractive sustainable anodes for LIB by Armand and workers, with a large lithium uptake occurring at $1 \mathrm{~V}$ and leading to the high initial capacity of $300 \mathrm{mAh} / \mathrm{g}$ (Armand et al., 2009). Two groups simultaneously tested the advantages of terephthalatebased electrodes to emerging KIB. At C/20, Deng et al. reported a stable capacity of $180 \mathrm{mAh} / \mathrm{g}$ for 100 cycles for dipotassium teraphtalate $\left(\mathrm{K}_{2} \mathrm{C}_{8} \mathrm{H}_{4} \mathrm{O}_{4}\right.$, hereafter named $\left.\mathrm{K}_{2} \mathrm{TP}\right)$, with KFSI (1M) in EC:DMC as electrolyte (Deng et al., 2017). A slightly better performance were presented by Chen et al. with $\mathrm{KPF}_{6}$ based electrolytes (Lei et al., 2017) (Figure 8). Interestingly, $\mathrm{K}_{2} \mathrm{TP}$ is obtained by a first potassiation of theraphtalic acid. Then, the redox process occurs at the two conjugated carboxylate groups and is facilitated by the flexible layered structure. The corresponding working potential is very low $0.6 \mathrm{~V}$, making $\mathrm{K}_{2} \mathrm{TP}$ suitable for application as negative electrode materials. The electrochemical process was carefully followed by FTIR and XPS, and the crucial role of the SEI film formed when DME is used as solvent was evidenced. In fact by replacing the latter by carbonate-based solvents both limited reversible capacities as well as fast capacity decay were observed.
Later, nanocomposites made of $\mathrm{K}_{2} \mathrm{TP}$ and carbon nanotubes was implemented in a full KIB with potassium-rich iron hexacyanoferrate as cathode material and a $\mathrm{KClO}_{4}$-based electrolyte (Liao et al., 2017). Without potassium metal, the electrochemical evaluation in full cell shows the absence of side reactions and improved cycling performance. Looking at other teraphatalate-based compounds, average capacities of $146 \mathrm{mAh} / \mathrm{g}$ for 200 cycles at $60 \mathrm{~mA} / \mathrm{g}$ were obtained for cobalt teraphtalate (CoTP) with KFSI (1 M) in EC:DMC (Fan C. et al., 2017). More simply, the direct use of the common and commercially available terephthalic acid enabled the access to capacities up to $240 \mathrm{mAh} / \mathrm{g}$ for 150 cycles at $500 \mathrm{~mA} / \mathrm{g}$ (Wang C. et al., 2018).

Other organic molecules based on carboxylates with an extended aromatic skeleton were investigated with the hope that larger $\pi$ conjugation might improve intermolecular electron percolation. With potassium $1,1^{\prime}$-biphenyl- $4,4^{\prime}$-dicarboxylate $\left(\mathrm{K}_{2} \mathrm{BPDC}\right)$ and potassium 4,4'-E-stilbenedicarboxylate ( $\left.\mathrm{K}_{2} \mathrm{SBDC}\right)$, low potassiation potentials at 0.35 and $0.55 \mathrm{~V}$ are observed, respectively. Although cycling capacities are logically lower than $\mathrm{K}_{2} \mathrm{TP}$, they are still promising with for example $143 \mathrm{mAh} / \mathrm{g}$ at $200 \mathrm{~mA} / \mathrm{g}$ and $100 \mathrm{mAh} / \mathrm{g}$ at $1,000 \mathrm{~mA} / \mathrm{g}$ for $\mathrm{K}_{2} \mathrm{BPDC}$ (Li et al., 2017). In the same spirit, the group of Wang developed azobenzene-4, $4^{\prime}$-dicarboxylic acid potassium salts with an azo group as the redox center (Liang et al., 2019).

Among the organic systems, also a series of oxocarbon salts $\left[\mathrm{M}_{2}(\mathrm{CO})_{\mathrm{n}}\right.$, with $\mathrm{n}$ ranging from 4 to 6$]$ were prepared and investigated as negative electrodes in LIB NIB, and KIB (Zhao Q. et al., 2016). It was surprisingly found that $\mathrm{K}_{2} \mathrm{C}_{6} \mathrm{O}_{6}$ and $\mathrm{K}_{2} \mathrm{C}_{5} \mathrm{O}_{5}$ allow an ultrafast $\mathrm{K}$-ion insertion/extraction. As an example, the discharge capacity of $\mathrm{K}_{2} \mathrm{C}_{6} \mathrm{O}_{6}$ is $212 \mathrm{mAh} / \mathrm{g}$ at $0.2 \mathrm{C}$, while $164 \mathrm{mAh} / \mathrm{g}$ are maintained at $10 \mathrm{C}$, using $\mathrm{KPF}_{6}(1.25 \mathrm{M})$ in DME electrolyte. The higher electrical conductivity of $\mathrm{K}_{2} \mathrm{C}_{6} \mathrm{O}_{6}$ than the lithium and sodium analogs was proposed to explain such surprising high-rate performance. The electrochemical potassiation of $\mathrm{K}_{2} \mathrm{C}_{6} \mathrm{O}_{6}$ proceeds in two-step, and the higher
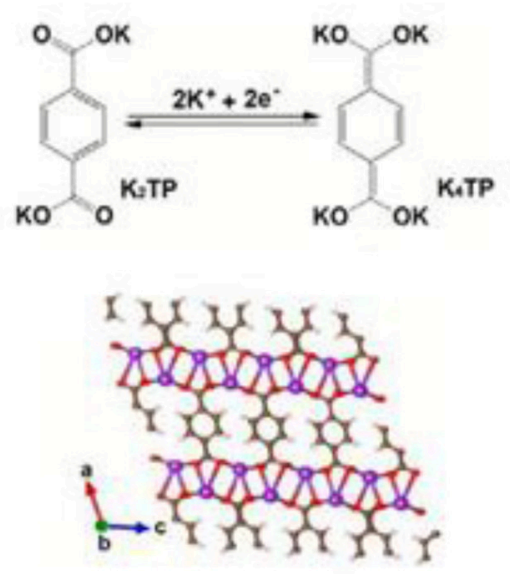
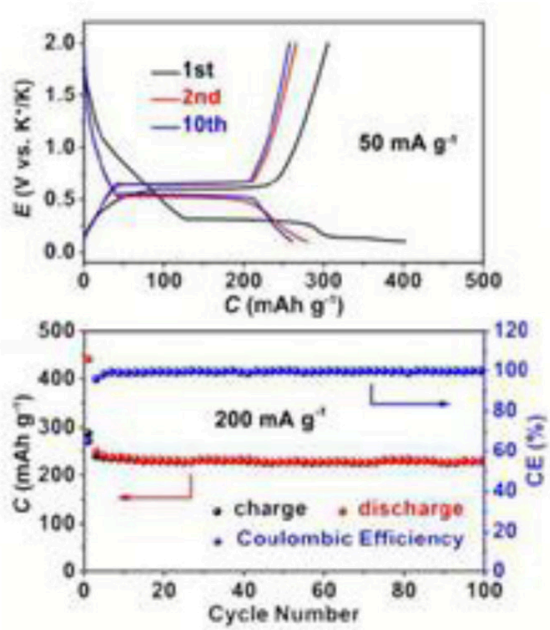

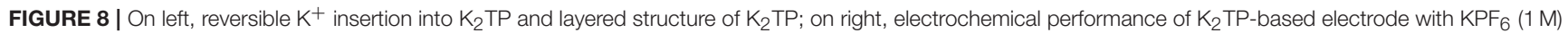
in DME electrolyte. Adapted from Lei et al. (2017) with permission from the Royal Society of Chemistry. 

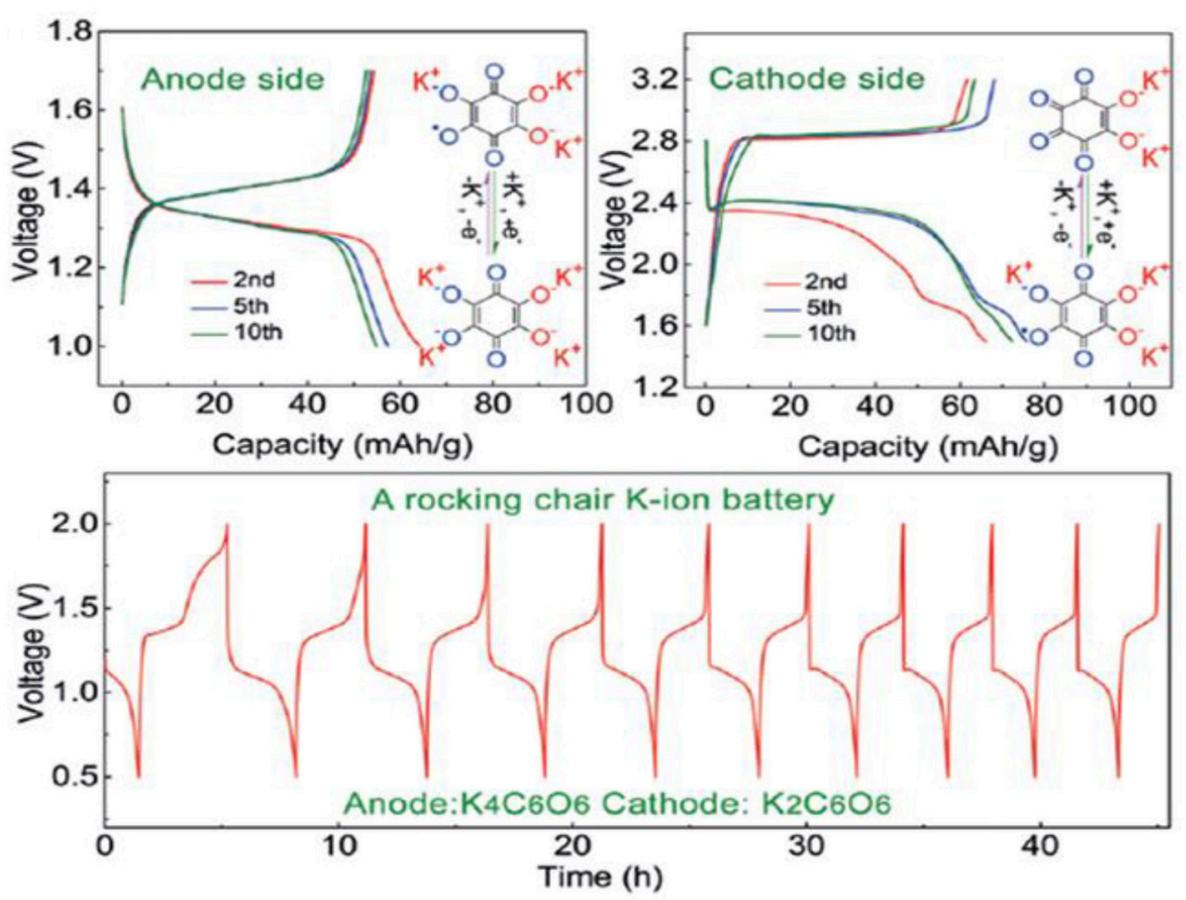

FIGURE 9 | Example of full organic $\mathrm{KIB}$ cycled at the current density of $25 \mathrm{mAh} / \mathrm{g}$ with oxocarbons $\mathrm{K}_{4} \mathrm{C}_{6} \mathrm{O}_{6}$ and $\mathrm{K}_{2} \mathrm{C}_{6} \mathrm{O}_{6}$ as negative and positive electrodes, respectively. Reprinted with permission from Zhao Q. et al. (2016). Copyright (2016) WILEY-VCH Verlag GmbH \& Co. KGaA, Weinheim.

potential plateau at $2.4 \mathrm{~V}$ (reaction from $\mathrm{K}_{2} \mathrm{C}_{6} \mathrm{O}_{6}$ to $\mathrm{K}_{3} \mathrm{C}_{6} \mathrm{O}_{6}$ ) is too high for application as anode. Thanks to the important difference with the second potential plateau at $1.3 \mathrm{~V}$ (reaction from $\mathrm{K}_{3} \mathrm{C}_{6} \mathrm{O}_{6}$ to $\mathrm{K}_{4} \mathrm{C}_{6} \mathrm{O}_{6}$ ), the authors bypassed this issue by proposing a full $\mathrm{K}_{4} \mathrm{C}_{6} \mathrm{O}_{6} / \mathrm{K}_{2} \mathrm{C}_{6} \mathrm{O}_{6} \mathrm{KIB}$, showing a potential of $1.1 \mathrm{~V}$ and a limited total energy density of $35 \mathrm{Wh} / \mathrm{kg}$ (Figure 9).

Finally, it is important to mention a recent report on anodes based on vitamin K (Xue et al., 2018). Indeed, this biomolecule possess a quinone structure which makes them electrochemically active. Using commercially available vitamin $\mathrm{K}$ associated with graphene nanotubes, Xue et al. reported at $100 \mathrm{~mA} / \mathrm{g}$ a promising initial capacity of $300 \mathrm{mAh} / \mathrm{g}$, which remains quite high upon cycling (222 mAh/g after 100 cycles) or at high current rates (165 $\mathrm{mAh} / \mathrm{g}$ at $1,000 \mathrm{~mA} / \mathrm{g})$.

Organic electrode materials are interesting candidates since a large-scale low cost production can be forecasted. Unlike insertion-type materials, the size of the potassium ion does not affect the electrochemical performance, and the very recent works described above surprisingly underline that fast reactions are feasible for selected organic compounds. Rational electrode formulation of the organic material with carbon additives should further promote the overall cycling performance.

\section{GENERAL CONCLUSION AND PERSPECTIVES}

Efforts for discovering high-performance negative electrode materials for KIB logically follow the pathways previously taken when developing LIB and NIB. Owing to this past experience, starting from the same type of electrode materials and following the same methodologies, the research on negative electrode materials for KIB is rapidly advancing. However, the lack of new concepts only devoted to the electrochemistry of potassium can be regretted. A comparison of the electrochemical behavior in $\mathrm{KIB}, \mathrm{NIB}$, and LIB is thus helpful to understand the mechanism and forecast the limits in terms of performance.

Similarly to lithium ions, potassium ions can be electrochemically inserted into graphite. Consequently, graphite and carbonaceous-based materials have ben intensively investigated. However, the specific capacities and rate capabilities reported so far appear limited. Other insertion-type materials may show electrochemical reversible reaction with potassium ions, but the large size of the potassium ion may not ease the ionic diffusion in particularly constrained structures. Moreover, after a quite promising first discharge capacity, a large irreversible capacity loss is often observed because of a high degree of ion trapping in the host structure.

For alloying and conversion-type electrode materials involving phase transitions, the size of $\mathrm{K}$-ion is not expected to play a significant role. However, it influences directly the volumetric expansion, which is sometimes 4 times higher than that observed in case of lithium alloying. This important volume change represents a real limitation for large-scale application. Nevertheless, it can be mitigated by using specific formulations including binders and carbon additives or nanostructuring the active material such as it was widely done for the silicon in LIB (Franco Gonzalez et al., 2017). 
There is currently a growing interested toward designing hybrid systems combining battery and supercapacitor behavior working on the dual reaction of both cations and anions with the electrode materials (Fan L. et al., 2017; Fan et al., 2018). In this context, there is no doubt that playing with potassium ion as the electrochemical vector could be of interest, with for example some electrode materials listed above.

In a number of works, the electrolyte was pointed out as a key factor for the electrochemical performance of negative electrode materials. Most of the electrochemical measurements were done with $\mathrm{KPF}_{6}$ salt (Hwang et al., 2018), but KFSI seems more stable and allowed obtaining better capacity retentions and coulombic efficiencies with most negative electrode materials. For the solvent, the mix of EC/DEC was mostly reported, but also EC/DMC and EC/PC were considered. Many works were focused on the comparison of carbonate-based vs. etherbased electrolytes. A strong difference was observed for graphite, for which carbonate species in the electrolyte led to intercalation of $\mathrm{K}^{+}$between the graphene layers whereas ether electrolytes rather show co-intercalation mechanisms. Wellknown LIB electrolyte additives such as FEC or VC appear to be not suitable in KIB. Many efforts should therefore be done in the future to develop stable and performing electrolytes with appropriate additives. The high reactivity of metallic potassium needs to be taken into account in half-cells measurements because its presence alter both the electrochemical performance and the SEI formation. Indeed, potassium metal

\section{REFERENCES}

Allan, P. K., Griffin, J. M., Darwiche, A., Borkiewicz, O. J., Wiaderek, K. M., Chapman, K. W., et al. (2016). Tracking sodium-antimonide phase transformations in sodium-ion anodes: insights from operando pair distribution function analysis and solid-state NMR spectroscopy. J. Am. Chem. Soc. 138, 2352-2365. doi: 10.1021/jacs.5b13273

An, Y., Fei, H., Zeng, G., Ci, L., Xi, B., Xiong, S., et al. (2018). Commercial expanded graphite as a low-cost, long-cycling life anode for potassium-ion batteries with conventional carbonate electrolyte. J. Power Sourc. 378, 66-72. doi: 10.1016/j.jpowsour.2017.12.033

Armand, M., Grugeon, S., Vezin, H., Laruelle, S., Ribière, P., Poizot, P., et al. (2009). Conjugated dicarboxylate anodes for Li-ion batteries. Nat. Mater. 8, 120-125. doi: $10.1038 /$ nmat 2372

Beltrop, K., Beuker, S., Heckmann, A., Winter, M., and Placke, T. (2017). Alternative electrochemical energy storage: potassium-based dual-graphite batteries. Energy Environ. Sci. 10, 2090-2094. doi: 10.1039/C7EE01535F

Chen, L., Fiore, M., Wang, J., E., Ruffo, R., Kim, D.-K., and Longoni, G. (2018). Readiness level of sodium-ion battery technology: a materials review. Adv. Sustain. Syst. 2:1700153. doi: 10.1002/adsu.201700153

Cohn, A. P., Muralidharan, N., Carter, R., Share, K., Oakes, L., and Pint, C. L. (2016). Durable potassium ion battery electrodes from high-rate cointercalation into graphitic carbons. J. Mater. Chem. A 4, 14954-14959. doi: 10.1039/C6TA06797B

Darwiche, A., Fehse, M., Mahmoud, A., La Fontaine, C., Fraisse, B., Hermann, R., et al. (2018). The electrochemical sodiation of Sb investigated by operando Xray absorption and $121 \mathrm{Sb}$ mössbauer spectroscopy: what does one really learn? Batteries 4:25. doi: 10.3390/batteries4020025

Deng, Q., Pei, J., Fan, C., Ma, J., Cao, B., Li, C., et al. (2017). Potassium salts of para-aromatic dicarboxylates as the highly efficient organic anodes for low-cost K-ion batteries. Nano Energy 33, 350-355. doi: 10.1016/j.nanoen.2017.01.016 was shown to influence the electrolyte stability and the nature of the SEI at the other electrode/electrolyte interface via a cross-talk mechanism (Madec et al., 2018). Therefore, the search for efficient electrolytes for KIB should be better carried out in full cell configurations.

To conclude, all the categories of negative electrode materials described above show interesting features but also important limitations. Electrodes are composites formed with an active material, a binder and a conductive additive, with ratios that need to be optimized to improve the synergy among them. It seems clear that graphite or carbonaceous derivatives could be the core of the electrode; the addition of alloying materials could be of interest in order to boost the specific and/or volumetric capacity, while that of titanium-based or organic materials could allow controlling and minimizing the electrochemical phenomena occurring at the crucial electrode-electrolyte interface.

\section{AUTHOR CONTRIBUTIONS}

All authors listed have made a substantial, direct and intellectual contribution to the work, and approved it for publication.

\section{ACKNOWLEDGMENTS}

The authors thank the French National Research Agency for its support to through the Labex STORE-EX project (ANR-10LABX-76-01).

Dong, S., Li, Z., Xing, Z., Wu, X., Ji, X., and Zhang, X. (2018). Novel potassiumion hybrid capacitor based on an anode of $\mathrm{K}_{2} \mathrm{Ti}_{6} \mathrm{O}_{13}$ microscaffolds. ACS Appl. Mater. Interfaces 10, 15542-15547. doi: 10.1021/acsami.7b15314

Dong, Y., Wu, Z., Zheng, S., Wang, X., Qin, J., Wang, S., et al. (2017). Ti 3C 2 MXene-derived sodium/potassium titanate nanoribbons for high-performance sodium/potassium ion batteries with enhanced capacities. ACS Nano 11, 4792-4800. doi: 10.1021/acsnano.7b 01165

Eftekhari, A., and Kim, D.-W. (2018). Sodium-ion batteries: new opportunities beyond energy storage by lithium. J. Power Sourc. 395, 336-348. doi: 10.1016/j.jpowsour.2018.05.089

Er, D., Li, J., Naguib, M., Gogotsi, Y., and Shenoy, V. B. (2014). Ti3C2 MXene as a high capacity electrode material for metal ( $\mathrm{Li}, \mathrm{Na}, \mathrm{K}, \mathrm{Ca}$ ) ion batteries. ACS Appl. Mater. Interfaces 6, 11173-11179. doi: 10.1021/am5 $01144 \mathrm{q}$

Fan, C., Zhao, M., Li, C., Wang, C., Cao, B., Chen, X., et al. (2017). Investigating the electrochemical behavior of cobalt(II) terephthalate (CoC8H4O4) as the organic anode in K-ion battery. Electrochim. Acta 253, 333-338. doi: 10.1016/j.electacta.2017.09.078

Fan, L., Lin, K., Wang, J., Ma, R., and Lu, B. (2018). A nonaqueous potassiumbased battery-supercapacitor hybrid device. Adv. Mater. 30:1800804. doi: 10.1002/adma.201800804

Fan, L., Liu, Q., Chen, S., Lin, K., Xu, Z., and Lu, B. (2017). Potassiumbased dual ion battery with dual-graphite electrode. Small 13:1701011. doi: 10.1002/smll.201701011

Fang, G., Zhou, J., Pan, A., and Liang, S. (2018). Recent advances in aqueous zinc-ion batteries. ACS Energy Lett. 3, 2480-2501. doi: 10.1021/acsenergylett.8b01426

Franco Gonzalez, A., Yang, N. H., and Liu, R. S. (2017). Silicon anode design for lithium-ion batteries: progress and perspectives. J. Phys. Chem. C 121, 27775-27787. doi: 10.1021/acs.jpcc.7b07793 
Gabaudan, V., Berthelot, R., Stievano, L., and Monconduit, L. (2018a). Inside the alloy mechanism of $\mathrm{Sb}$ and Bi electrodes for K-ion batteries. J. Phys. Chem. C 122, 18266-18273. doi: 10.1021/acs.jpcc.8b04575

Gabaudan, V., Berthelot, R., Stievano, L., and Monconduit, L. (2018b). Electrochemical alloying of lead in potassium-ion batteries. ACS Omega 3, 12195-12200. doi: 10.1021/acsomega.8b01369

Han, C., Han, K., Wang, X., Wang, C., Li, Q., Meng, J., et al. (2018). Threedimensional carbon network confined antimony nanoparticle anodes for highcapacity K-ion batteries. Nanoscale 10, 6820-6826. doi: 10.1039/C8NR00237A

Han, J., Niu, Y., Bao, S. J., Yu, Y. N., Lu, S. Y., and Xu, M. (2016a). Nanocubic KTi 2 (PO 4) 3 electrodes for potassium-ion batteries. Chem. Commun. 52, 11661-11664. doi: 10.1039/C6CC06177J

Han, J., Xu, M., Niu, Y., Li, G. N., Wang, M., Zhang, Y., et al. (2016b). Exploration of K2Ti8O17 as an anode material for potassium-ion batteries. Chem. Commun. 52, 11274-11276. doi: 10.1039/C6CC05102B

Hosaka, T., Shimamura, T., Kubota, K., and Komaba, S. (2019). Polyanionic compounds for potassium-ion batteries. Chem. Rec. 19, 735-745. doi: 10.1002/tcr.201800143

Hui, J., Schorr, N. B., Pakhira, S., Qu, Z., Mendoza-Cortes, J. L., and RodríguezLópez, J. (2018). Achieving fast and efficient $\mathrm{K}+$ intercalation on ultrathin graphene electrodes modified by a $\mathrm{Li}+$ based solid-electrolyte interphase. J. Am. Chem. Soc. 140, 13599-13603. doi: 10.1021/jacs.8b08907

Hwang, J.-Y., Myung, S.-T., and Sun, Y.-K. (2018). Recent progress in rechargeable potassium batteries. Adv. Funct. Mater. 28:1802938. doi: 10.1002/adfm.201802938

Irisarri, E., Ponrouch, A., and Palacin, M. R. (2015). Review-hard carbon negative electrode materials for sodium-ion batteries. J. Electrochem. Soc. 162, A2476A2482. doi: 10.1149/2.0091514jes

Jian, Z., Hwang, S., Li, Z., Hernandez, A. S., Wang, X., Xing, Z., et al. (2017). Hardsoft composite carbon as a long-cycling and high-rate anode for potassium-ion batteries. Adv. Funct. Mater. 27:1700324. doi: 10.1002/adfm.201700324

Jian, Z., Luo, W., and Ji, X. (2015). Carbon electrodes for K-ion batteries. J. Am. Chem. Soc. 137, 11566-11569. doi: 10.1021/jacs.5b06809

Jian, Z., Xing, Z., Bommier, C., Li, Z., and Ji, X. (2016). Hard carbon microspheres: potassium-ion anode versus sodium-ion anode. Adv. Energy Mater. 6:1501874. doi: 10.1002/aenm.201501874

Kim, H., Kim, J. C., Bianchini, M., Seo, D.-H., Rodriguez-Garcia, J., and Ceder, G. (2018). Recent progress and perspective in electrode materials for K-ion batteries. Adv. Energy Mater. 8:1702384. doi: 10.1002/aenm.201702384

Kishore, B., G, V., and Munichandraiah, N. (2016). $\mathrm{K}_{2} \mathrm{Ti}_{4} \mathrm{O}_{9}$ : a promising anode material for potassium ion batteries. J. Electrochem. Soc. 163, A2551-A2554. doi: 10.1149/2.0421613jes

Komaba, S., Hasegawa, T., Dahbi, M., and Kubota, K. (2015). Potassium intercalation into graphite to realize high-voltage/high-power potassium-ion batteries and potassium-ion capacitors. Electrochem. Commun. 60, 172-175. doi: 10.1016/j.elecom.2015.09.002

Kubota, K., Dahbi, M., Hosaka, T., Kumakura, S., and Komaba, S. (2018). Towards K-ion and Na-ion batteries as "beyond Li-ion". Chem. Rec. 18, 459-479. doi: 10.1002/tcr.201700057

Lakshmi, V., Chen, Y., Mikhaylov, A. A., Medvedev, A. G., Sultana, I., Rahman, M. M., et al. (2017). Nanocrystalline SnS 2 coated onto reduced graphene oxide: demonstrating the feasibility of a non-graphitic anode with sulfide chemistry for potassium-ion batteries. Chem. Commun. 53, 8272-8275. doi: 10.1039/C7CC03998K

Lei, K., Li, F., Mu, C., Wang, J., Zhao, Q., Chen, C., et al. (2017). High Kstorage performance based on the synergy of dipotassium terephthalate and ether-based electrolytes. Energy Environ. Sci. 10, 552-557. doi: 10.1039/C6EE $03185 \mathrm{D}$

Lei, K., Wang, C., Liu, L., Luo, Y., Mu, C., Li, F., et al. (2018). A porous network of bismuth used as the anode material for high-energy-density potassiumion batteries. Angew. Chem. Int. Ed. 57, 4687-4691. doi: 10.1002/anie.2018 01389

Li, C., Deng, Q., Tan, H., Wang, C., Fan, C., Pei, J., et al. (2017). Para conjugated dicarboxylates with extended aromatic skeletons as the highly advanced organic anodes for K-ion battery. ACS Appl. Mater. Interfaces 9, 27414-27420. doi: 10.1021/acsami.7b08974

Li, P., Wang, W., Gong, S., Lv, F., Huang, H., Luo, M., et al. (2018). Hydrogenated $\mathrm{Na}_{2} \mathrm{Ti}_{3} \mathrm{O}_{7}$ epitaxially grown on flexible $\mathrm{N}$-doped carbon sponge for potassium-ion batteries. ACS Appl. Mater. Interfaces 10, 37974-37980. doi: 10.1021/acsami.8b11354

Lian, P., Dong, Y., Wu, Z.-S., Zheng, S., Wang, X., Wang, S., et al. (2017). Alkalized $\mathrm{Ti}_{3} \mathrm{C}_{2}$ MXene nanoribbons with expanded interlayer spacing for high-capacity sodium and potassium ion batteries. Nano Energy 40, 1-8. doi: 10.1016/j.nanoen.2017.08.002

Liang, Y., Luo, C., Wang, F., Hou, S., Liou, S.-C., Qing, T., et al. (2019). An organic anode for high temperature potassium-ion batteries. Adv. Energy Mater. 9:1802986. doi: 10.1002/aenm.201802986

Liao, J., Hu, Q., Yu, Y., Wang, H., Tang, Z., Wen, Z., et al. (2017). A potassium-rich iron hexacyanoferrate/dipotassium terephthalate@carbon nanotube composite used for K-ion full-cells with an optimized electrolyte. J. Mater. Chem. A 5, 19017-19024. doi: 10.1039/C7TA05460B

Lin, X., Huang, J., and Zhang, B. (2019). Correlation between the microstructure of carbon materials and their potassium ion storage performance. Carbon N. Y. 143, 138-146. doi: 10.1016/j.carbon.2018.11.001

Liu, C., Luo, S., Huang, H., Wang, Z., Wang, Q., Zhang, Y., et al. (2018). Potassium vanadate $\mathrm{K}_{0.23} \mathrm{~V}_{2} \mathrm{O}_{5}$ as anode materials for lithium-ion and potassium-ion batteries. J. Power Sourc. 389, 77-83. doi: 10.1016/j.jpowsour.2018.04.014

Liu, D., Huang, X., Qu, D., Zheng, D., Wang, G., Harris, J., et al. (2018).Confined phosphorus in carbon nanotube-backboned mesoporous carbon as superior anode material for sodium/potassium-ion batteries. Nano Energy 52, 1-10. doi: 10.1016/j.nanoen.2018.07.023

Liu, Q., Fan, L., Ma, R., Chen, S., Yu, X., Yang, H., et al. (2018). Super longlife potassium-ion batteries based on an antimony@carbon composite anode. Chem. Commun. 54, 11773-11776. doi: 10.1039/C8CC05257C

Liu, Y., Li, Y., Li, F., Liu, Y., Yuan, X., Zhang, L., et al. (2019). Conversion of $\mathrm{Ti}_{2} \mathrm{AlC}$ to $\mathrm{C}-\mathrm{K}_{2} \mathrm{Ti}_{4} \mathrm{O}_{9}$ via a $\mathrm{KOH}$ assisted hydrothermal treatment and its application in lithium-ion battery anodes. Electrochim. Acta 295, 599-604. doi: 10.1016/j.electacta.2018.11.003

Liu, Y., Tai, Z., Zhang, J., Pang, W. K., Zhang, Q., Feng, H., et al. (2018). Boosting potassium-ion batteries by few-layered composite anodes prepared via solution-triggered one-step shear exfoliation. Nat. Commun. 9:3645. doi: 10.1038/s41467-018-05786-1

Luo, W., Wan, J., Ozdemir, B., Bao, W., Chen, Y., Dai, J., et al. (2015). Potassium ion batteries with graphitic materials. Nano Lett. 15, 7671-7677. doi: 10.1021/acs.nanolett.5b03667

Ma, Z., MacFarlane, D. R., and Kar, M. (2019). Mg cathode materials and electrolytes for rechargeable mg batteries: a review. Batter. Supercaps 2, 115-127. doi: 10.1002/batt.201800102

Madec, L., Gabaudan, V., Gachot, G., Stievano, L., Monconduit, L., and Martinez, H. (2018). Paving the way for K-ion batteries: role of electrolyte reactivity through the example of Sb-based electrodes. ACS Appl. Mater. Interfaces 10, 34116-34122. doi: 10.1021/acsami.8b08902

McCulloch, W. D., Ren, X., Yu, M., Huang, Z., and Wu, Y. (2015). Potassium-ion oxygen battery based on a high capacity antimony anode. ACS Appl. Mater. Interfaces 7, 26158-26166. doi: 10.1021/acsami.5b08037

Messinger, R. J., Ménétrier, M., Salager, E., Boulineau, A., Duttine, M., Carlier, D., et al. (2015). Revealing defects in crystalline lithium-ion battery electrodes by solid-state NMR: applications to LiVPO ${ }_{4}$ F. Chem. Mater. 27, 5212-5221. doi: 10.1021/acs.chemmater.5b01234

Minakshi, M., Singh, P., Carter, M., and Prince, K. (2008). The Zn$\mathrm{MnO}$ [sub 2] battery: the influence of aqueous $\mathrm{LiOH}$ and $\mathrm{KOH}$ electrolytes on the intercalation mechanism. Electrochem. Solid-State Lett. 11:A145. doi: 10.1149/1.2932056

Okamoto, Y. (2014). Density functional theory calculations of alkali metal ( $\mathrm{Li}$, $\mathrm{Na}$, and K) graphite intercalation compounds. J. Phys. Chem. C 118, 16-19. doi: $10.1021 /$ jp4063753

Ponrouch, A., Frontera, C., Bardé, F., and Palacín, M. R. (2016). Towards a calcium-based rechargeable battery. Nat. Mater. 15, 169-172. doi: $10.1038 /$ nmat4462

Ramireddy, T., Kali, R., M., Jangid, K., Srihari, V., Poswal, H., K., and Mukhopadhyay, A. (2017). Insights into electrochemical behavior, phase evolution and stability of Sn upon K-alloying/de-alloying via In Situ Studies. J. Electrochem. Soc. 164, A2360-A2367. doi: 10.1149/2.0481712jes

Ren, X., Zhao, Q., McCulloch, W. D., and Wu, Y. (2017). $\mathrm{MoS}_{2}$ as a longlife host material for potassium ion intercalation. Nano Res. 10, 1313-1321. doi: 10.1007/s12274-016-1419-9 
Sangster, J. M. (2010). K-P (Potassium-Phosphorus) system. J. Phase Equilibria Diffus. 31, 68-72. doi: 10.1007/s11669-009-9614-y

Share, K., Cohn, A. P., Carter, R., Rogers, B., and Pint, C. L. (2016b). Role of nitrogen-doped graphene for improved high-capacity potassium ion battery anodes. ACS Nano 10, 9738-9744. doi: 10.1021/acsnano.6b05998

Share, K., Cohn, A. P., Carter, R. E., and Pint, C. L. (2016a). Mechanism of potassium ion intercalation staging in few layered graphene from in situ Raman spectroscopy. Nanoscale 8, 16435-16439. doi: 10.1039/C6NR04084E

Shimizu, M., Yatsuzuka, R., Koya, T., Yamakami, T., and Arai, S. (2018). Tin oxides as a negative electrode material for potassium-ion batteries. ACS Appl. Energy Mater. 1, 6865-6870. doi: 10.1021/acsaem.8b01209

Su, D., McDonagh, A., Qiao, S. Z., and Wang, G. (2017). High-capacity aqueous potassium-ion batteries for large-scale energy storage. Adv. Mater. 29:1604007. doi: 10.1002/adma.201604007

Subbaiah, T., Sanjay, K., Biswal, A., Chandra Tripathy, B., and Minakshi, M. (2015). Electrolytic manganese dioxide (EMD): a perspective on worldwide production, reserves and its role in electrochemistry. RSC Adv. 5, 58255-58283. doi: $10.1039 / C 5 R A 05892 A$

Sultana, I., Rahman, M. M., Chen, Y., and Glushenkov, A. M. (2018). Potassiumion battery anode materials operating through the alloying-dealloying reaction mechanism. Adv. Funct. Mater. 28:1703857. doi: 10.1002/adfm.201703857

Sultana, I., Rahman, M. M., Liu, J., Sharma, N., Ellis, A. V., Chen, Y., et al. (2019). Antimony-carbon nanocomposites for potassium-ion batteries: Insight into the failure mechanism in electrodes and possible avenues to improve cyclic stability. J. Power Sourc. 413, 476-484. doi: 10.1016/j.jpowsour.2018.12.017

Sultana, I., Rahman, M. M., Mateti, S., Ahmadabadi, V. G., Glushenkov, A. M., and Chen, Y. (2017b). K-ion and Na-ion storage performances of $\mathrm{Co}_{3} \mathrm{O}_{4}$ $\mathrm{Fe}_{2} \mathrm{O}_{3}$ nanoparticle-decorated super $\mathrm{P}$ carbon black prepared by a ball milling process. Nanoscale 9, 3646-3654. doi: 10.1039/C6NR09613A

Sultana, I., Rahman, M. M., Ramireddy, T., Chen, Y., and Glushenkov, A. M. (2017a). High capacity potassium-ion battery anodes based on black phosphorus. J. Mater. Chem. A 5, 23506-23512. doi: 10.1039/C7TA02483E

Sultana, I., Ramireddy, T., Rahman, M. M., Chen, Y., and Glushenkov, A. M. (2016). Tin-based composite anodes for potassium-ion batteries. Chem. Commun. 52, 9279-9282. doi: 10.1039/C6CC03649J

Tarascon, J.-M. (2010). Is lithium the new gold? Nat. Chem. 2, 510-510. doi: $10.1038 /$ nchem. 680

Tzolov, M. B., and Iliev, M. N. (1992). Raman scattering from monoalkali (Na$\mathrm{Sb}$ and $\mathrm{K}-\mathrm{Sb}$ ), bialkali (Na-K-Sb) and multialkali (Na-K-Sb-Cs) photocathodes. Thin Solid Films 213, 99-102. doi: 10.1016/0040-6090(92)90481-P

Van Noorden, R. (2014). A better battery. Nature 507:26. doi: 10.1038/507026a

Wang, C., Tang, W., Yao, Z., Chen, Y., Pei, J., and Fan, C. (2018). Using an organic acid as a universal anode for highly efficient Li-ion, $\mathrm{Na}$-ion and K-ion batteries. Org. Electron. 62, 536-541. doi: 10.1016/j.orgel.2018.06.027

Wang, H., Wang, L., Wang, L., Xing, Z., Wu, X., Zhao, W., et al. (2018). Phosphorus particles embedded in reduced graphene oxide matrix to enhance capacity and rate capability for capacitive potassium-ion storage. Chem. A Eur. J. 24, 13897-13902. doi: 10.1002/chem.201802753

Wang, L., Yang, J., Li, J., Chen, T., Chen, S., Wu, Z., et al. (2019). Graphite as a potassium ion battery anode in carbonate-based electrolyte and ether-based electrolyte. J. Power Sources 409, 24-30. doi: 10.1016/j.jpowsour.2018.10.092

Wang, Q., Zhao, X., Ni, C., Tian, H., Li, J., Zhang, Z., et al. (2017). Reaction and capacity-fading mechanisms of tin nanoparticles in potassium-ion batteries. J. Phys. Chem. C 121, 12652-12657. doi: 10.1021/acs.jpcc.7b03837

Wang, W., Zhou, J., Wang, Z., Zhao, L., Li, P., Yang, Y., et al. (2018). Short-range order in mesoporous carbon boosts potassium-ion battery performance. $A d v$. Energy Mater. 8:1701648. doi: 10.1002/aenm.201701648

Wang, Y., Wang, Z., Chen, Y., Zhang, H., Yousaf, M., Wu, H., et al. (2018). Hyperporous sponge interconnected by hierarchical carbon nanotubes as a high-performance potassium-ion battery anode. Adv. Mater. 30:1802074. doi: 10.1002/adma.201802074

Wei, Z., Wang, D., Li, M., Gao, Y., Wang, C., Chen, G., et al. (2018). Fabrication of hierarchical potassium titanium phosphate spheroids: a host material for sodium-ion and potassium-ion storage. Adv. Energy Mater. 8:1801102. doi: 10.1002/aenm.201801102

Wessells, C. D., Huggins, R. A., and Cui, Y. (2011). Copper hexacyanoferrate battery electrodes with long cycle life and high power. Nat. Commun. 2, 550-555. doi: 10.1038/ncomms1563
Wu, X., Zhao, W., Wang, H., Qi, X., Xing, Z., Zhuang, Q., et al. (2018b). Enhanced capacity of chemically bonded phosphorus/carbon composite as an anode material for potassium-ion batteries. J. Power Sourc. 378, 460-467. doi: 10.1016/j.jpowsour.2017.12.077

Xie, Y., Dall'Agnese, Y., Naguib, M., Gogotsi, Y., Barsoum, M. W., Zhuang, H. L., et al. (2014). Prediction and characterization of MXene nanosheet anodes for non-lithium-ion batteries. ACS Nano 8, 9606-9615. doi: 10.1021/nn503921j

Xing, Z., Qi, Y., Jian, Z., and Ji, X. (2017). Polynanocrystalline graphite: a new carbon anode with superior cycling performance for K-ion batteries. ACS Appl. Mater. Interfaces 9, 4343-4351. doi: 10.1021/acsami.6b06767

Xiong, P., Bai, P., Tu, S., Cheng, M., Zhang, J., Sun, J., et al. (2018b). Red Phosphorus Nanoparticle@3D Interconnected Carbon Nanosheet Framework Composite for Potassium-Ion Battery Anodes. Small 14, 1802140. doi: 10.1002/smll.201802140

Xiong, P., Zhao, X., and Xu, Y. (2018a). Nitrogen-doped carbon nanotubes derived from metal - organic frameworks for potassium-ion battery anodes. ChemSusChem 11, 202-208. doi: 10.1002/cssc.201701759

Xu, Y., Zhang, C., Zhou, M., Fu, Q., Zhao, C., Wu, M., et al. (2018). Highly nitrogen doped carbon nanofibers with superior rate capability and cyclability for potassium ion batteries. Nat. Commun. 9:1720. doi: 10.1038/s41467-018-04190-Z

Xue, Q., Li, D., Huang, Y., Zhang, X., Ye, Y., Fan, E., et al. (2018). Vitamin K as a high-performance organic anode material for rechargeable potassium ion batteries. J. Mater. Chem. A 6, 12559-12564. doi: 10.1039/C8TA03921F

Yamamoto, H., Muratsubaki, S., Kubota, K., Fukunishi, M., Watanabe, H., Kim, J., et al. (2018). Synthesizing higher-capacity hard-carbons from cellulose for Na- and K-ion batteries. J. Mater. Chem. A 6, 16844-16848. doi: 10.1039/C8TA05203D

Yang, H., Li, H., Li, J., Sun, Z., He, K., Cheng, H. M., et al. (2019). The rechargeable aluminum battery: opportunities and challenges. Angew. Chemie Int. Ed. doi: 10.1002/anie.201814031. [Epub ahead of print].

Yang, S., Zhang, M., Wu, X., Wu, X., Zeng, F., Li, Y., et al. (2019). The excellent electrochemical performances of $\mathrm{ZnMn}_{2} \mathrm{O}_{4} / \mathrm{Mn}_{2} \mathrm{O}_{3}$ : the composite cathode material for potential aqueous zinc ion batteries. J. Electroanal. Chem. 832, 69-74. doi: 10.1016/j.jelechem.2018.10.051

Yi, Z., Lin, N., Zhang, W., Wang, W., Zhu, Y., and Qian, Y. (2018). Preparation of $\mathrm{Sb}$ nanoparticles in molten salt and their potassium storage performance and mechanism. Nanoscale 10, 13236-13241. doi: 10.1039/C8NR03829E

Zhang, N., Cheng, F., Liu, J., Wang, L., Long, X., Liu, X., et al. (2017). Rechargeable aqueous zinc-manganese dioxide batteries with high energy and power densities. Nat. Commun. 8, 1-9. doi: 10.1038/s41467-017-00467-x

Zhang, Q., Mao, J., Pang, W. K., Zheng, T., Sencadas, V., Chen, Y., et al. (2018). Boosting the potassium storage performance of alloy-based anode materials via electrolyte salt chemistry. Adv. Energy Mater. 2018:1703288. doi: 10.1002/aenm.201703288

Zhang, R., Bao, J., Wang, Y., and Sun, C. F. (2018). Concentrated electrolytes stabilize bismuth-potassium batteries. Chem. Sci. 9, 6193-6198. doi: 10.1039/C8SC01848K

Zhang, W., Mao, J., Li, S., Chen, Z., and Guo, Z. (2017). Phosphorus-based alloy materials for advanced potassium-ion battery anode. J. Am. Chem. Soc. 139, 3316-3319. doi: 10.1021/jacs.6b12185

Zhang, W., Pang, W. K., Sencadas, V., and Guo, Z. (2018b). Understanding highenergy-density $\mathrm{Sn}_{4} \mathrm{P}_{3}$ anodes for potassium-ion batteries. Joule 2, 1534-1547. doi: 10.1016/j.joule.2018.04.022

Zhang, W., Wu, Z., Zhang, J., Liu, G., Yang, N. H., Liu, R. S., et al. (2018a). Unraveling the effect of salt chemistry on long-durability high-phosphorusconcentration anode for potassium ion batteries. Nano Energy 53, 967-974. doi: 10.1016/j.nanoen.2018.09.058

Zhang, Z., Li, M., Gao, Y., Wei, Z., Zhang, M., Wang, C., et al. (2018). Fast potassium storage in hierarchical $\mathrm{Ca}_{0} .5 \mathrm{Ti}_{2}\left(\mathrm{PO}_{4}\right)_{3} @ \mathrm{C}$ microspheres enabling high-performance potassium-ion capacitors. Adv. Funct. Mater. 28:1802684. doi: $10.1002 / \mathrm{adfm} .201802684$

Zhao, J., Zou, X., Zhu, Y., Xu, Y., and Wang, C. (2016). Electrochemical intercalation of potassium into graphite. Adv. Funct. Mater. 26, 8103-8110. doi: 10.1002/adfm.201602248

Zhao, Q., Wang, J., Lu, Y., Li, Y., Liang, G., and Chen, J. (2016). Oxocarbon salts for fast rechargeable batteries. Angew. Chemie Int. Ed. 55, 12528-12532. doi: 10.1002/anie.201607194 
Zhao, X., Tang, Y., Ni, C., Wang, J., Star, A., Xu, Y., et al. (2018). Free-standing nitrogen-doped cup-stacked carbon nanotube mats for potassium-ion battery anodes. ACS Appl. Energy Mater. 1, 1703-1707. doi: 10.1021/acsaem.8b00182

Zhao, X., Xiong, P., Meng, J., Liang, Y., Wang, J., and Xu, Y. (2017). High rate and long cycle life porous carbon nanofiber paper anodes for potassium-ion batteries. J. Mater. Chem. A 5, 19237-19244. doi: 10.1039/C7TA04264G

Zheng, J., Yang, Y., Fan, X., Ji, G., Ji, X., and Wang, C. (2019). Extremely stable antimony-carbon composite anodes for potassium-ion batteries. Energy Environ. Sci. 12, 615-623. doi: 10.1039/C8EE02836B

Zhu, Y.-H., Yang, X., Sun, T., Wang, S., Zhao, Y.-L., Yan, J.-M., et al. (2018). Recent progresses and prospects of cathode materials for non-aqueous potassium-ion batteries. Electrochem. Energy Rev. 1, 548-566. doi: 10.1007/s41918-018-0019-7
Conflict of Interest Statement: The authors declare that the research was conducted in the absence of any commercial or financial relationships that could be construed as a potential conflict of interest.

Copyright (c) 2019 Gabaudan, Monconduit, Stievano and Berthelot. This is an open-access article distributed under the terms of the Creative Commons Attribution License (CC BY). The use, distribution or reproduction in other forums is permitted, provided the original author(s) and the copyright owner(s) are credited and that the original publication in this journal is cited, in accordance with accepted academic practice. No use, distribution or reproduction is permitted which does not comply with these terms. 